NUCLEAR SCIENCE AND ENGINEERING: 155, 1-17 (2007)

\title{
A New Approximation for the Neutron Albedo
}

\author{
Ronald C. Brockhoff and J. Kenneth Shultis* \\ Kansas State University, Department of Mechanical and Nuclear Engineering \\ Manhattan, Kansas 66506-2503
}

Received September 16, 2005

Accepted January 18, 2006

\begin{abstract}
Empirical parameters for a new fast-neutron differential dose albedo formula are presented for water, concrete, iron, and lead and for ten energy bands between 0.1 and $10.0 \mathrm{MeV}$. Data are also presented for ${ }^{252} \mathrm{Cf}$ spontaneous fission neutrons, 14-MeV neutrons, and thermal neutrons. The 24parameter approximation, based on modern dose units, agrees with MCNP-calculated values within $10 \%$. Revised data are also presented for a five-parameter secondary-photon albedo formula, proposed earlier by Maerker and Muckenthaler, that is within 20\% of MCNP values for the four materials. Finally, these revised albedo formulas are applied to the problem of thermal neutrons transmitted through a three-legged duct and compared to previous experimental results.
\end{abstract}

\section{INTRODUCTION}

The calculation of how radiation incident on a surface is reemitted through the surface toward some point of interest is a frequently encountered problem in radiation shielding. Transport techniques are generally required for detailed estimation of reflected doses. But, under certain circumstances a simplified approach based on the albedo concept can be used with great effect. These conditions are ${ }^{1}$

1. that the displacement on the surface between the entrance and exit of the radiation is very small compared to the problem dimensions

2. that the reflecting medium is optically thick

3. that scattering between the radiation source and surface and between the surface and point of interest is insignificant.

The use of albedo techniques is central to many radiation streaming codes and has been widely used as an alternative to much more expensive transport calculations.

Key to the albedo technique is the availability of either a large set of albedo data or, preferably, an empirical formula that approximates the albedo over the range of source energies and incident and exit radiation direc-

*E-mail: jks@ksu.edu tions involved in a particular problem. In this paper only the neutron albedo, which is generally much greater than that for photons, is addressed. Previously proposed neutron albedo approximating formulas have been based on limited energy-angular ranges; a single reflecting material; old cross-section data; and, most important, obsolete fluence-to-dose response functions. In this paper, differential neutron dose albedo functions, based on modern cross-section and response function data, are presented.

\section{I.A. Previous Neutron Albedo Studies}

There are many data in the literature for neutron albedos and for the associated secondary-photon doses. Early significant contributions included those of Maerker and Muckenthaler, ${ }^{2}$ who performed both detailed calculational and experimental evaluations for concrete, and Allen, Futterer, and Wright, ${ }^{3}$ who made albedo calculations for monoenergetic fast neutrons incident on a variety of materials. French and Wells ${ }^{4}$ derived an empirical formula for the azimuthally averaged data of Allen, Futterer, and Wright, which is restricted to incident directions of $<70$ deg from the surface normal. Also using the same fast-neutron data, Song, Huddleston, and Chilton proposed a fast-neutron formula with azimuthal dependence. ${ }^{5}$ Maerker and Muckenthaler in their 1965 study also proposed a 24 -parameter formula obtained by a fit 


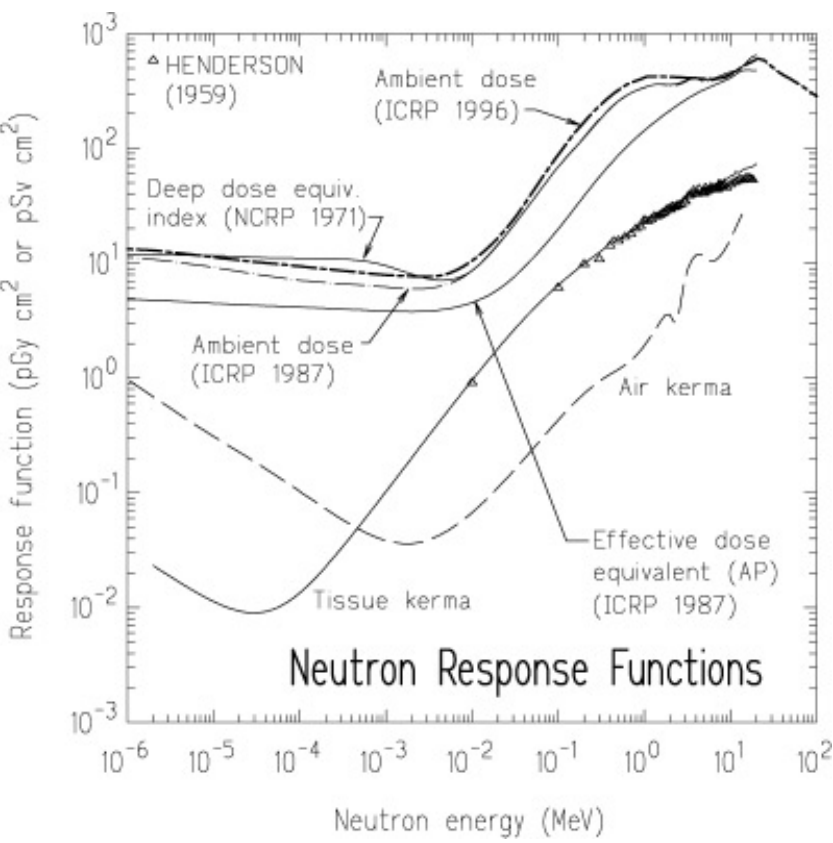

Fig. 1. Comparison of modern neutron dose functions with kerma response functions, used in much early albedo work. Sources are Henderson, ${ }^{16}$ tissue/air kerma, ${ }^{1}$ NCRP-1971 (Ref. 17), ICRP-1987 (Ref. 18), and ICRP-1996 (Ref. 19).

to their calculated concrete albedos. ${ }^{2}$ Extensive computerized sets of fast-neutron albedo data are also available, such as SAIL (Ref. 6), BREESE-II (Ref. 7), and that of Wang. ${ }^{8}$

A neutron albedo approximation for intermediateenergy neutrons $(0.5 \mathrm{eV}$ to $0.2 \mathrm{MeV})$ has been proposed by Coleman et al. for steel-reinforced concrete. ${ }^{9}$ Formulas for the thermal-neutron albedo have been proposed by Wells ${ }^{10}$ and Maerker and Muckenthaler, ${ }^{11}$ and an analytical one-speed transport result by Chandrasekhar ${ }^{12}$ has also been studied for use as a thermal-neutron albedo formula. ${ }^{11,13}$

Although not strictly part of the albedo concept, the emergence of secondary gamma photons from a surface upon which neutrons are incident has been studied by Wells, ${ }^{10}$ Selph, ${ }^{14}$ and Cavanaugh, ${ }^{15}$ and formulas for the secondary-photon albedo from concrete have been suggested by Wells ${ }^{10}$ and Maerker and Muckenthaler. ${ }^{11}$ For a more detailed survey of previous studies on the neutron albedo, the reader is referred to Selph ${ }^{14}$ and Shultis and Faw. ${ }^{1}$

\section{I.B. Need for Revised Neutron Albedos}

Unlike compilations or formulas for albedos for monoenergetic incident photons, it is difficult to interpolate similar neutron albedos because of the many resonances in the neutron cross sections. To account for the usual continuous distribution of fast neutrons, it is preferable to obtain albedos for incident neutrons in various contiguous fast-neutron energy bins. However, many previous fast-neutron albedo studies are for monoenergetic sources and hence are of limited practical utility.

Moreover, most neutron albedo approximating formulas are based on very old neutron interaction data, on only a few incident directions, and are available for only a single reflecting material. For example, Maerker and Muckenthaler's 24-parameter, fast-neutron, dose albedo formula for concrete is based on only four incident angles $(45,50,75$, and $85 \mathrm{deg}$ with respect to the surface normal), old cross-section data, and the Henderson (tissue kerma) fluence-to-dose response function available before 1962 (Ref. 2).

Perhaps the most important reason to revisit the neutron albedo is that unlike photon albedos, neutron dose albedos are extremely dependent on the dose response function used. Previous neutron albedo work has mostly been based on air kerma or the Henderson (tissue kerma) response function. But, as seen from Fig. 1, these response functions are quite different from modern neutron response functions. ${ }^{a}$ Moreover, the ratios between these various response functions are strong functions of the neutron energy, and hence, dose albedos calculated with one response function cannot be converted to another by simply multiplying by a single conversion constant (as can be done for most photon dose albedos).

\section{THEORY}

To calculate the albedo one first finds the current of particles emerging from the plane surface of a homogeneous half-space that is illuminated uniformly by a plane-parallel, monoenergetic beam of radiation incident on the surface at an angle $\theta_{o}$ with respect to the surface normal $\mathbf{n}$ (see Fig. 2). The incident particle flow, in dose units, across a unit area of the surface is related to the incident fluence $\Phi_{o}$ as

$$
J_{n}^{i n}=\left|\mathbf{n} \cdot \boldsymbol{\Omega}_{o}\right| \Phi_{o} R\left(E_{o}\right)=\Phi_{o} \cos \theta_{o} R\left(E_{o}\right),
$$

${ }^{\text {a }}$ The air and tissue kermas do not include the quality factor for the secondary charged particles. Also, the kermas, which are point dosimetric concepts, generally decrease as the incident neutron energy decreases because the kinetic energy of the secondary changed particles (primarily from scattering interactions) also must decrease. The kermas are seen to have a minimum and begin to rise at very low energies as a result of $(n, p)$ reactions with nitrogen. By contrast, the ambient dose and dose equivalents are based on dosimetric phantoms that moderate and absorb incident neutrons resulting, generally, in capture photons that also contribute to the dose. This contribution, not included in the kermas, causes these response functions to become relatively flat below $10 \mathrm{keV}$. 


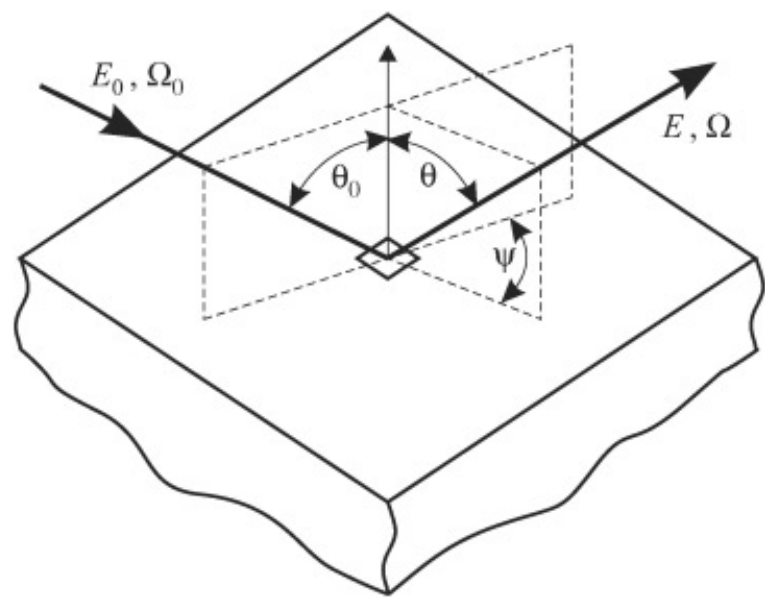

Fig. 2. Particles incident and reflected from the surface of a half-space.

where $R\left(E_{o}\right)$ is the fluence-to-dose conversion factor (response function) for the incident radiation of energy $E_{o}$. The total flow or current out of a unit area of the surface in a unit solid angle about the direction $\boldsymbol{\Omega}(\theta, \psi), \mathbf{n} \cdot \boldsymbol{\Omega}>0$, again in dose units, can be expressed as

$$
\begin{aligned}
J_{n}^{\text {out }}(\theta, \psi) & =\int_{0}^{E_{\max }} J_{n}^{\text {out }}(E, \theta, \psi) R(E) d E \\
& =\int_{0}^{E_{\max }} \Phi(E, \theta, \psi) \cos \theta R(E) d E,
\end{aligned}
$$

where $J_{n}^{\text {out }}(\theta, \psi, E)$ and $\Phi(\theta, \psi, E)$ are, respectively, the angular energy-dependent flow and fluence at the surface, and $E_{\max }$ is the maximum neutron energy.

The differential dose albedo is defined as the ratio of the outward to inward flows, ${ }^{\mathrm{b}}$ namely, ${ }^{1,20}$

$$
\alpha_{D}\left(E_{o}, \theta_{o} ; \theta, \psi\right) \equiv \frac{J_{n}^{\text {out }}(\theta, \psi)}{J_{n}^{\text {in }}},
$$

which, from Eq. (2), yields

$\alpha_{D}\left(E_{o}, \theta_{o} ; \theta, \psi\right)=\frac{1}{J_{n}^{\text {in }}} \int_{0}^{E_{\max }} J_{n}^{\text {out }}(\theta, \psi, E) R(E) d E$.

Finally, in this study, the albedo of Eq. (4) is averaged over various fast-neutron energy intervals or a fission spectrum to obtain albedos for a corresponding range of

${ }^{\mathrm{b}}$ Many early albedo studies used slightly different definitions, such as the ratio of outward flow to incident fluence or the ratio of outward fluence to incident fluence, and it is important to distinguish among them when comparing different albedo results. incident neutron energies by selecting the incident neutron energy from the appropriate distribution.

\section{MCNP CALCULATION OF THE ALBEDO}

We used the MCNP general-purpose Monte Carlo code $^{21}$ to calculate the albedo reflected from thick slabs of various materials. In particular, we considered a homogeneous cylindrical slab surrounded by a vacuum. The incident neutrons were modeled by a point monodirectional source positioned just inside the center of the circular scoring (reflecting) surface. This was done to facilitate scoring because all particles crossing this surface must be outgoing (reflected) particles. The slab thickness and radius were sufficiently large $(1000 \mathrm{~cm})$ so that negligible numbers of neutrons were transmitted through the slab or radial surface. The energy of the source neutrons was sampled uniformly over an energy group or from a fission neutron distribution.

For the albedo calculation, the outgoing current from the reflecting surface must be tallied in terms of the outgoing polar angle $\theta$ and the outgoing azimuthal angle $\psi$. MCNP provides a surface current tally, called the F1 tally, that scores the number of particles crossing a surface in all directions, namely,

$$
\begin{aligned}
\text { Tally F1 }= & \int_{A} \int_{-1}^{1} \int_{0}^{2 \pi} \int_{E} J(\vec{r}, E, \theta, \psi) \\
& \times R(E) d E d \cos \theta d \psi d A,
\end{aligned}
$$

where $R(E)$ is a user-specified response function. However, by default MCNP does not allow the user to bin this current tally in terms of both $\theta$ and $\psi$. Therefore, the tally was modified through the use of the TALLYX user routine. This option, which permits the user to modify a tally, was used here to disaggregate the F1 tally for reflected particles into a set of angular bins or subtallies, each of which corresponded to a small range of the $\theta$ and $\psi$ reflection directions.

In this study we used $N_{\theta}=9$ intervals equally spaced between 0 and $90 \mathrm{deg}$ in polar angle and $N_{\psi}=18$ intervals equally spaced between 0 and $180 \mathrm{deg}$ in azimuth. Because the reflected photon field is symmetric about $\psi=180 \mathrm{deg}$, particles reflected with $\psi>180 \mathrm{deg}$ can be binned in the corresponding (360 deg $-\psi$ ) bin. Thus, a total of $N_{\theta} \times N_{\psi}=162$ angular bins was used. The bin number $i b u$ corresponding to a particular value of $\theta$ and $\psi$ is

$$
i b u=\operatorname{int}\left(\frac{\theta N_{\theta}}{90}\right)+N_{\theta} i n t\left(\frac{\psi N_{\psi}}{180}\right)+1
$$

To score related quantities, such as the outgoing angles for a particle passing through the surface, the user must specify the scoring bin limits on the "FU card." Here, the appropriate FU card would be FU1 1 160i 162. 
The tallies in each scoring bin are normalized to one source photon and thus represent, in the notation of Sec. II,

$$
\begin{aligned}
\operatorname{tally} \operatorname{bin}(i)= & \frac{2}{J_{n}^{\text {in }}} \int_{\Delta \cos \theta_{i}} \int_{\Delta \psi_{i}} \int_{0}^{\infty} J_{n}^{\text {out }}(E, \theta, \psi) \\
& \times R(E) d(\cos \theta) d \psi d E,
\end{aligned}
$$

where $\Delta \cos \theta \Delta \psi$ is the solid angle covered by $\operatorname{bin}(i)$. The factor of 2 in this result arises from the $\psi$-symmetry used in the binning process. Finally, if $\theta$ and $\psi$ are the centroid angles of a bin with a tally denoted by $T(\theta, \psi)$, the differential dose albedo is estimated from

$$
\alpha_{D}\left(\Delta E, \theta_{o} ; \theta, \psi\right)=\frac{T(\theta, \psi)}{2 \Delta \cos \theta \Delta \psi},
$$

where $\Delta \cos \theta$ varies from bin to bin and $\Delta E$ represents the energy distribution from which energies of the incident neutrons are uniformly sampled.

\section{RESULTS}

The MCNP albedo model was used to calculate the albedo for nine monodirectional angles of incidence $\theta_{o}$ of $5,15,25,35,45,55,65,75$, and 85 deg on infinite slabs of natural iron, water, natural lead, and NBS 04 concrete. NBS 04 concrete represents "ordinary" concrete as proposed by the American National Standards Institute. ${ }^{22}$ The dose albedo was calculated for two response functions, namely, the ambient dose equivalent and the effective dose equivalent for anteroposterior geometry. ${ }^{18}$ Thirteen different incident energy distributions were considered: ten fast-neutron contiguous energy groups with group boundaries of $0.1,0.2,0.4,0.6,0.8,1$, 2, 4, 6, 8, and $10 \mathrm{MeV}$; a room-temperature thermalneutron spectrum; a ${ }^{252} \mathrm{Cf}$ fission neutron spectrum; and monoenergetic 14-MeV neutrons.

The many statistical tests provided by MCNP were carefully examined to ensure meaningful results were obtained for all 162 angular tally bins. For the MCNP simulations performed in this study, a sufficient number of histories were run to ensure that the relative error for every tally bin was $<10 \%$. Furthermore, when possible, a sufficient number of histories were run to obtain relative errors of $<1 \%$. In addition, all simulations were performed until the variance of the variance (VOV) was below 0.1 , and the histories were examined to make sure the VOV decreased inversely with the number of histories. This second step was particularly important since the VOV is particularly sensitive to large history scores and can indicate if these large scores are being undersampled.

To verify that valid albedos were calculated, a comparison of our MCNP model was made to the most detailed previous albedo study, performed by Maerker and
Muckenthaler. ${ }^{2}$ They used the Henderson response function and a concrete composition of $\mathrm{H} 9.43 \times 10^{21}$, O $4.76 \times 10^{22}$, Ca $7.80 \times 10^{21}$, and Si $1.185 \times 10^{22}$ atoms / $\mathrm{cm}^{3}$, with a density of $2.35 \mathrm{~g} / \mathrm{cm}^{3}$. To their experimental measurements they fit the following 24-parameter approximating formula:

$$
\begin{aligned}
\alpha_{D_{2}}\left(\Delta E_{o}, \theta_{o} ; \theta, \psi\right) & \\
= & \frac{1}{1+\left(K_{1} \cos \theta_{o} / \cos \theta\right)} \sum_{m=0}^{8} G_{m} P_{m}\left(\cos \theta_{s}\right) \\
& +\frac{1}{1+K_{2}\left(\Delta E_{o}, \theta_{o}, \theta\right)} \sum_{k=0}^{4} B_{k} P_{k}\left(\cos \theta_{s}\right),
\end{aligned}
$$

where

$$
K_{2}\left(\Delta E_{o}, \theta_{o}, \theta\right)=\sum_{i=0}^{2} \cos ^{i} \theta \sum_{j=0}^{2} a_{i j} \cos ^{j} \theta_{o} .
$$

The 24 parameters $G_{m}, B_{k}, K_{1}$, and $a_{i j}$ vary with the source energy band $\Delta E_{o}$. We used the same response function and concrete composition to calculate albedos with MCNP. An example comparison between the approximating formula of Eq. (9) and our calculated albedos is shown in Fig. 3. The parameters for Eq. (9) were obtained by a fit to experimental data, and considering their fit was not always within $10 \%$ of the data, the agreement between our results and Maerker and Muckenthaler's approximation is quite reasonable.

In general, the neutron albedo exhibits several characteristics, as seen in Fig. 3. Albedos resulting from neutrons incident at nearly normal angles (i.e., $5 \mathrm{deg}$ ) are essentially independent of azimuthal angle. In addition, the results for this case indicate that more neutrons are emitted normally to the surface than are emitted at grazing angles. As the angle of incidence increases, the albedo data become peaked in the forward direction, and the overall magnitude of the albedo increases. This result is again expected because, for grazing angles of incidence, neutrons usually do not penetrate deeply into the reflecting media. As a result, the neutrons have a high chance of being reemitted. For normal incidence, neutrons usually penetrate much more deeply into the reflecting media, which decreases the probability of their reemission. In addition, if a neutron penetrates a large distance into the reflecting media, the highest probability of escape is in a direction normal to the slab because this represents the shortest escape distance for reemission.

Based on the good agreement between Eq. (9) and our MCNP results, it seemed that this approximating equation would be suitable for use as an approximation of the neutron albedo for other reflecting media. Unfortunately, after significant testing it became apparent that the Maerker and Muckenthaler approximation could not be extended to other materials over a wide range of energies. Values for the 24-fit coefficients for the albedo 


\section{Concrete}
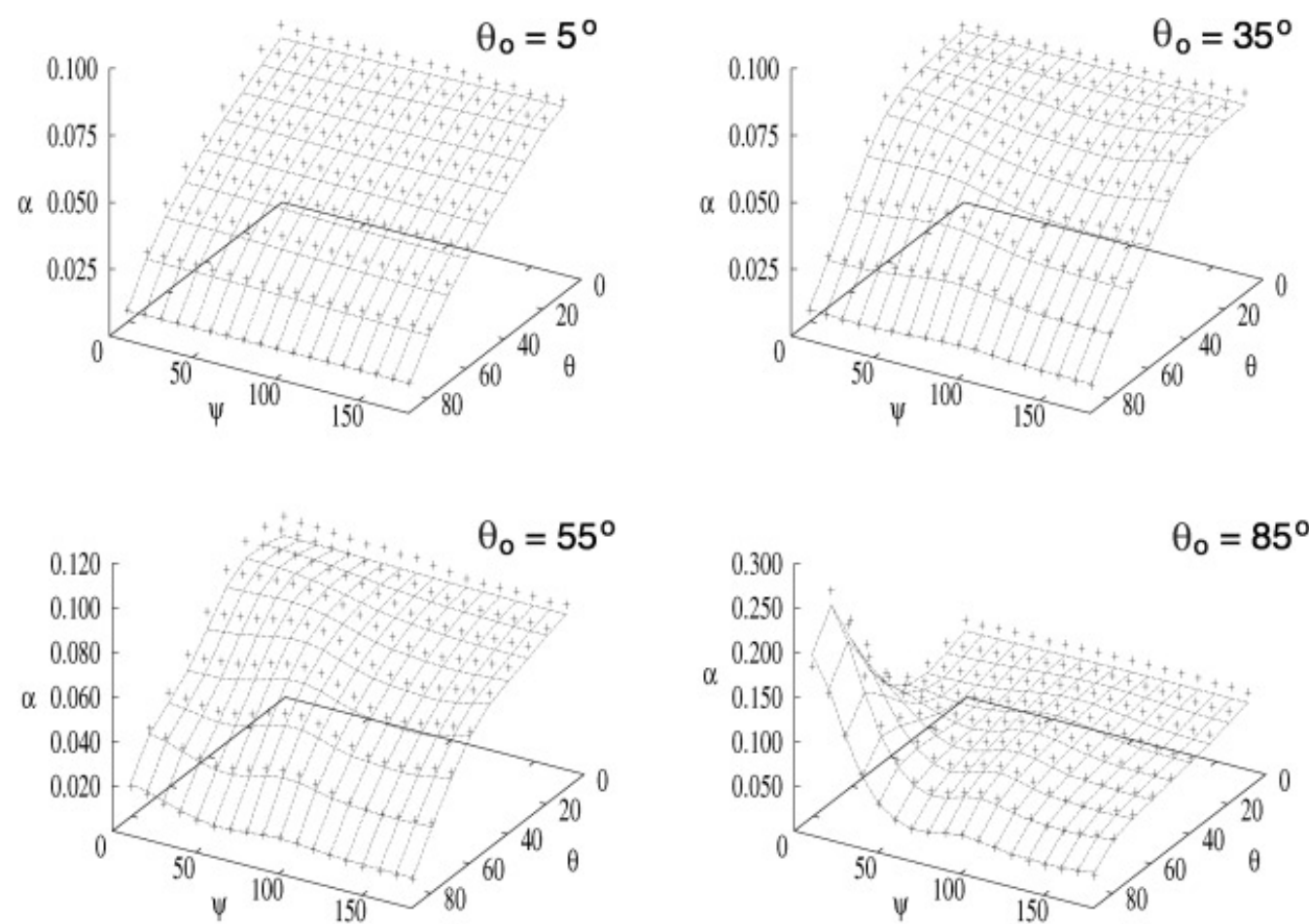

Fig. 3. Neutron differential Henderson albedo $\alpha_{D}\left(E_{o}, \theta_{o} ; \theta, \psi\right)$ for 6- to 8-MeV neutrons incident on a slab of concrete for $\theta_{o}=5,35,55$, and $85 \mathrm{deg}$. Comparison of MCNP results (crosses) and Maerker and the Muckenthaler analytic approximation (surface) of Eq. (9).

approximation of Eq. (9) were determined by minimizing, with a multidimensional simplex procedure, ${ }^{23}$ the absolute maximum deviation between the MCNP albedo data and the fit. However, the fits obtained using this procedure resulted in deviations in excess of $50 \%$ for many cases. For instance, the fit for $6.0-$ to $8.0-\mathrm{MeV}$ neutrons incident on concrete resulted in a minimum maximum deviation of only $14.24 \%$ but resulted in minimum maximum deviations of $32.34 \%$ for iron, $56.53 \%$ for lead, and $16.70 \%$ for water.

\section{IV.A. A New Fast-Neutron Albedo Approximation}

Because the Maerker and Muckenthaler approximation did not provide sufficient accuracy for the fast-neutron albedo for lead and iron, an alternative approximation was formulated. To obtain this new approximation, the neutron albedo was separated into two components. The first component consisted of the neutrons emitted from the reflecting media as a result of a single scatter within the media, and the second component consisted of the neutrons emitted from reflecting media that had undergone two or more scatters. Indeed, in Eq. (9) the first term apparently is an approximation for single-scattered neutrons while the second term attempts to account for multiple-scattered neutrons.

Initial attempts sought to find better approximations for these two components of the albedo. For elastic scattering, the single-scatter dose albedo is rigorously given by ${ }^{24}$

$$
\begin{aligned}
\alpha_{D}^{1}\left(E_{o}, \theta_{o} ; \theta, \psi\right) & \\
= & \frac{\mu_{s}\left(E, \theta_{s}^{c}\right)}{\mu\left(E_{o}\right)} \frac{R(E)}{R\left(E_{o}\right)}\left(1+\frac{\mu(E)}{\mu\left(E_{o}\right)} \frac{\cos \theta_{o}}{\cos \theta}\right)^{-1} \\
& \times \frac{\sin \theta_{s}^{c}}{\sin \theta_{s}}\left[1+\frac{\cos \theta_{s}}{A}\left\{1-\left(\frac{\sin \theta_{s}}{A}\right)^{2}\right\}^{-1 / 2}\right],
\end{aligned}
$$

where $E=E_{o}\left[(1+\alpha)+(1-\alpha) \cos \theta_{s}^{c}\right] / 2, \alpha=(A-1)^{2} /$ $(A+1)^{2}$, and $\mu_{s}\left(E, \theta_{s}^{c}\right)$ is the differential scattering interaction coefficient for scattering through an angle $\theta_{s}^{c}$ in the center-of-mass system. After extensive experimentation it was determined that the effect of $\mu_{s}\left(E, \theta_{s}^{c}\right)$ on the overall albedo dominates the structure of the albedo for 
most energies. For the case of hydrogenous media, this effect is particularly pronounced since the laboratory scattering angle cannot exceed $\pi / 2$.

Efforts were also taken to use other approximations for the portion of the albedo that results from neutrons that undergo multiple scatters within the reflecting media before being reemitted. For heavy $A$ materials, scattering results in little energy loss, and often, scattering is nearly isotropic. Thus, a number of approximations of the thermal-neutron albedo were analyzed to determine their overall effectiveness at approximating this multiscattered albedo component. In particular, an analytical result for one-speed particles in an isotropically scattering medium due to Chandrasekhar ${ }^{12}$ was investigated, namely,

$$
\alpha=\frac{\kappa}{4 \pi} \frac{1}{1+\cos \theta_{o} / \cos \theta} H\left(\kappa, \cos \theta_{o}\right) H(\kappa, \cos \theta),
$$

where $\kappa$ is the probability of scattering when an interaction occurs (i.e., the ratio of the scattering to the total interaction coefficients) and $H(\kappa, \cos \theta)$ is Chandrasekhar's $H$-function. ${ }^{1,12}$ An approximation of the $H$-function that is within $5 \%$ for $\kappa$ between 0.8 and 1.0 can be expressed as

$$
H(\kappa, \mu)=\frac{A+B \kappa+C \mu+D \mu^{2}+E \mu^{3}}{1+F \kappa+G \kappa^{2}+H \kappa^{3}+I \mu} .
$$

This approximation was obtained by fitting Eq. (13) to actual $H$-function data. Values for the constants are given in Table I. Indeed, Eq. (12) with only a single parameter $\kappa$ was found to fit the thermal-neutron albedo for iron and lead with minimum maximum deviations of only 5.5 and $4.0 \%$, respectively. However, it is a poor approximation to the thermal-neutron albedo for water and concrete, with minimum maximum deviations of 45 and $33 \%$,

\section{TABLE I}

Fit Parameters for the Chandrasekhar $H$-Function Approximation of Eq. (13)

\begin{tabular}{|c|r|}
\hline Parameter & \multicolumn{1}{|c|}{ Value } \\
\hline$A$ & 0.075272288 \\
$B$ & -0.063133359 \\
$C$ & 0.021092012 \\
$D$ & -0.026070382 \\
$E$ & 0.009381680 \\
$F$ & -3.179279300 \\
$G$ & 3.485739800 \\
$H$ & -1.294988700 \\
$I$ & -0.005750418 \\
\hline
\end{tabular}

respectively, a result not unexpected since scattering from hydrogen is far from isotropic in the laboratory system.

Using these and other approximations with numerous free parameters, we obtained results that suffered from the same shortcomings as Maerker and Muckenthaler's attempt at adding the two albedo components. In hindsight, this is not too surprising because even though Eq. (11) represents the first-scattered component exactly, Eq. (12) is not very good for multiple scattering by light $A$ materials since the scattering is far from isotropic in the laboratory system.

At this point, an attempt to recombine the terms into a single term was undertaken. Notice that both components given by Eqs. (11) and (12) include a term of the basic form ${ }^{\mathrm{c}}$

$$
\frac{1}{1+C \cos \theta_{o} / \cos \theta}
$$

where $C$ equals 1 for the multiscattered component and $\mu(E) / \mu\left(E_{o}\right)$ for the first-scattered component. Even though this parameter is different for the two components, it was found through a series of trials that the rollover effect of the differential albedo is best approximated for a value of $C$, which is a function of both $\cos \theta$ and $\cos \theta_{o}$. Therefore, if the rollover effect of the two albedo components can be combined, then it should be possible to combine the two components into a single expression for the albedo.

The value of $\mu_{s}\left(E, \theta_{s}^{c}\right)$ dominates the structure of the neutron albedo for most energies. Because this cross section is typically represented by a Legendre expansion, it was used to approximate the first-scatter behavior in the overall approximation. In addition, since the multiscattered component of the albedo also exhibits preferential forward scattering for grazing angles of incidence, a Legendre expansion should help offset some of the inaccuracies inherent in the relation proposed by Chandrasekhar. In fact, when the two albedo components are combined into a single term and a Legendre expansion is applied to the result, an approximation of the albedo is obtained that is more accurate than Maerker and Muckenthaler's approximation. After much experimentation, we arrived at the following form of a singleterm approximation:

$$
\begin{aligned}
\alpha_{D}\left(\Delta E_{o}, \theta_{o} ; \theta, \psi\right)= & \frac{H\left(\kappa_{1}, \cos \theta_{o}\right) H\left(\kappa_{2}, \cos \theta\right)}{1+K_{1}\left(E_{o}, \theta_{o} ; \theta\right) / \cos \theta} \\
& \times \sum_{i=0}^{N} B_{i} P_{i}\left(\cos \theta_{s}\right),
\end{aligned}
$$

${ }^{\mathrm{c}}$ As $\theta \rightarrow 90 \mathrm{deg}$, this term causes the albedo to decrease or "roll over" from the larger values at small values of $\theta$. This rollover effect is quite apparent in the examples of Fig. 3. 
where

$$
K_{1}\left(E_{o}, \theta_{o} ; \theta\right)=\sum_{i=0}^{2} \cos ^{i} \theta \sum_{j=0}^{2} A_{i j} \cos \theta_{o}^{j} .
$$

The number of fitting parameters is $N+12\left[\kappa_{1}, \kappa_{2}\right.$, $9 A_{i j}$, and $\left.(N+1) B_{i}\right]$. The number of terms used in the Legendre expansion, $N+1$, determines the accuracy of the approximation. For most reflecting media and neutron energies, the use of a nine-term expansion results in fits with a maximum deviation of $<10 \%$. However, for extreme cases, such as 8 - to $10-\mathrm{MeV}$ neutrons incident on concrete, water, iron, and lead, a nine-term expansion results in maximum deviations of $6.96,12.05,31.06$, and $10.46 \%$. By contrast, a 13-term expansion (24 parameters) results in maximum deviations of $6.95,9.08$, 8.97 , and $8.13 \%$ for the same reflecting media. Besides approximating the albedo for all the discrete energy groups, the 24-parameter formula also worked well for thermal neutrons, ${ }^{252} \mathrm{Cf}$ fission neutrons, and $14-\mathrm{MeV}$ neutrons.

The fit coefficients for the albedo approximation of Eq. (15) were determined by minimizing, with a multidimensional simplex procedure, ${ }^{23}$ the absolute maximum deviation between the MCNP albedo data and the fit. The resulting coefficients for four reflecting materials and different source energy groups are presented in Tables II through V. Example comparisons between the MCNP data (crosses) and the values from the approximation of Eq. (15) (grid vertices) are shown in Fig. 4.

Overall, the results obtained using the approximation of Eq. (15) fit well the raw MCNP albedo data. The maximum deviation is within $10 \%$ for all cases. The examples shown in Fig. 4 compare the fit to the MCNP albedo data for 6- to 8-MeV neutrons incident on concrete. For this energy interval, use of Maerker and Muckenthaler's relation resulted in maximum deviations of $14.24,32.34,56.53$, and $16.70 \%$ for concrete, iron, lead, and water, respectively. By contrast, using the approximation given in Eq. (15) results in maximum deviations of $6.32,7.61,8.52$, and $7.15 \%$, respectively, for the same reflecting materials.

\section{IV.B. Secondary-Photon Albedos}

The MCNP code also was used to obtain a set of secondary-photon albedo data based on modern response functions. ${ }^{\mathrm{d}}$ The secondary albedo arises from the production inelastic and capture gamma rays that are radiated from the reflecting surface. In general, the secondary-photon albedo is independent of the azimuthal angle as a consequence of the isotropic emission of secondary gamma rays. Also of note is that the mag-

\footnotetext{
${ }^{\mathrm{d}}$ For photon energies above $100 \mathrm{keV}$, the various photon response functions are nearly equal, but at low energies significant differences occur. ${ }^{1}$
}

nitude of the secondary-photon dose albedo is usually considerably less than that of the neutron dose albedo, and consequently, a high-accuracy approximation for the secondary-photon albedo is generally not needed. Thus, in this study, a relatively simple approximation was developed.

Maerker and Muckenthaler provided detailed calculations for thermal neutrons incident on concrete and proposed a relation to approximate the secondary-photon albedo, namely, ${ }^{2}$

$$
\begin{aligned}
\alpha_{D_{2}}^{(n, \gamma)}\left(\theta_{o}, \theta\right)=\cos ^{A_{1}}(\theta)[ & A_{2}+A_{3} \cos \left(\theta_{o}\right) \\
& \left.+A_{4} \cos ^{2}\left(\theta_{o}\right)\right] A_{5},
\end{aligned}
$$

where the parameters $A_{1}, A_{2}, A_{3}, A_{4}$, and $A_{5}$ are functions of the reflecting media and the energy of the incident neutrons. This approximation was used in the present study to represent the secondary-photon albedos.

The fit coefficients for the albedo approximation of Eq. (17) were again determined by minimizing, with a multidimensional simplex procedure, ${ }^{23}$ the absolute maximum deviation between the MCNP albedo data and the fit. The resulting coefficients for four reflecting materials and different source energies are presented in Tables VI through IX. An example comparison between the MCNP data (crosses) and the values from the five-parameter albedo approximation of Eq. (17) is shown in Fig. 5.

This approximation is not as accurate as the approximations presented for the neutron albedo. Use of this approximation can result in deviations in excess of $20 \%$ in some cases. Therefore, for problems in which the secondary-photon albedo needs to be calculated accurately over a small range of reflected directions, Eq. (17) should be used carefully. For most problems, the secondary-photon albedo is usually small in comparison with the neutron albedo, and the use of this approximation should yield acceptable results.

\section{EXAMPLE APPLICATION: A DUCT PROBLEM}

As an example of the utility of the albedo approximations, we modified MCNP to use the albedo functions developed in this study for solving problems of thermal neutrons streaming through multilegged ducts. ${ }^{24}$ The modified MCNP code applies the albedo to a particle when it reaches a duct surface, whereas in standard Monte Carlo transport calculations, the particle is tracked throughout the duct wall, which may result in emission of a neutron. Using the albedo technique at the duct surface is much more efficient than using standard Monte Carlo techniques, in which an incident particle may undergo many interactions before reemerging from the surface, thereby requiring significantly more computational effort than is required for the albedo technique. 
TABLE II

Parameters for the 24-Term Approximation of Eq. (15) of the Neutron Albedo for Concrete Based on Ambient Dose Equivalent

\begin{tabular}{|c|c|c|c|c|c|c|}
\hline $\begin{array}{l}\text { Energy } \\
(\mathrm{MeV})\end{array}$ & $\begin{array}{c}B_{0} \\
B_{6} \\
B_{12} \\
A_{1,2}\end{array}$ & $\begin{array}{c}B_{1} \\
B_{7} \\
A_{0,0} \\
A_{2,0}\end{array}$ & $\begin{array}{c}B_{2} \\
B_{8} \\
A_{0,1} \\
A_{2,1}\end{array}$ & $\begin{array}{c}B_{3} \\
B_{9} \\
A_{0,2} \\
A_{2,2}\end{array}$ & $\begin{array}{c}B_{4} \\
B_{10} \\
A_{1,0} \\
\kappa_{1}\end{array}$ & $\begin{array}{c}B_{5} \\
B_{11} \\
A_{1,1} \\
\kappa_{2}\end{array}$ \\
\hline 0.10 to 0.20 & $\begin{array}{l}0.0310058 \\
0.0000529 \\
0.0000954 \\
0.3424365\end{array}$ & $\begin{array}{r}0.0079036 \\
-0.0001221 \\
0.0039811 \\
0.2091158\end{array}$ & $\begin{array}{r}0.0087912 \\
-0.0001975 \\
0.5068846 \\
0.3370075\end{array}$ & $\begin{array}{r}0.0062737 \\
-0.0000960 \\
0.0105815 \\
-0.5585166\end{array}$ & $\begin{array}{r}0.0029994 \\
0.0000477 \\
-0.5428182 \\
0.9159864\end{array}$ & $\begin{array}{l}0.0009364 \\
0.0000535 \\
0.1168724 \\
0.9704829\end{array}$ \\
\hline 0.20 to 0.40 & $\begin{array}{r}0.0305840 \\
0.0003188 \\
-0.0000817 \\
0.0207392\end{array}$ & $\begin{array}{l}0.0033702 \\
0.0003548 \\
0.0068881 \\
0.1804531\end{array}$ & $\begin{array}{l}0.0070808 \\
0.0002247 \\
0.4763392 \\
0.1076931\end{array}$ & $\begin{array}{r}0.0043717 \\
0.0000251 \\
0.0387856 \\
-0.0612162\end{array}$ & $\begin{array}{r}0.0015211 \\
-0.0003007 \\
-0.5787132 \\
0.9114627\end{array}$ & $\begin{array}{r}0.0004325 \\
-0.0000684 \\
0.2292421 \\
0.9772167\end{array}$ \\
\hline 0.40 to 0.60 & $\begin{array}{r}0.0378538 \\
-0.0010647 \\
-0.0000469 \\
0.0252979\end{array}$ & $\begin{array}{r}0.0212337 \\
-0.0005923 \\
0.0906067 \\
0.0853344\end{array}$ & $\begin{array}{r}0.0141692 \\
-0.0010205 \\
0.1070549 \\
0.0096570\end{array}$ & $\begin{array}{r}0.0037221 \\
-0.0002173 \\
0.4564914 \\
0.1060794\end{array}$ & $\begin{array}{r}0.0003630 \\
-0.0000607 \\
-0.3424352 \\
0.9174654\end{array}$ & $\begin{array}{r}-0.0004349 \\
0.0005663 \\
0.0523915 \\
0.9953164\end{array}$ \\
\hline 0.60 to 0.80 & $\begin{array}{r}0.0336213 \\
0.0007243 \\
-0.0001044 \\
0.0026744\end{array}$ & $\begin{array}{l}0.0151799 \\
0.0006396 \\
0.0025973 \\
0.1334834\end{array}$ & $\begin{array}{r}0.0081274 \\
0.0006094 \\
0.5611226 \\
-0.0968205\end{array}$ & $\begin{array}{r}0.0040338 \\
0.0001064 \\
0.0411399 \\
-0.0893064\end{array}$ & $\begin{array}{r}0.0011740 \\
-0.0000868 \\
-0.4697157 \\
0.8871664\end{array}$ & $\begin{array}{r}0.0006816 \\
-0.0002743 \\
0.1524706 \\
0.9898409\end{array}$ \\
\hline 0.80 to 1.00 & $\begin{array}{r}0.0521323 \\
0.0001755 \\
0.0003944 \\
-0.1091755\end{array}$ & $\begin{array}{l}0.0181552 \\
0.0001753 \\
0.0081107 \\
0.2708193\end{array}$ & $\begin{array}{r}0.0222947 \\
-0.0007409 \\
0.6205748 \\
0.0324836\end{array}$ & $\begin{array}{r}0.0075743 \\
-0.0006731 \\
0.0188183 \\
0.1329039\end{array}$ & $\begin{array}{r}0.0020112 \\
-0.0006460 \\
-0.3031898 \\
0.8479228\end{array}$ & $\begin{array}{l}0.0013746 \\
0.0006971 \\
0.0370416 \\
0.9822085\end{array}$ \\
\hline 1.00 to 2.00 & $\begin{array}{r}0.0426823 \\
0.0007958 \\
-0.0001557 \\
-0.0769485\end{array}$ & $\begin{array}{l}0.0191216 \\
0.0013026 \\
0.0155465 \\
0.0919803\end{array}$ & $\begin{array}{l}0.0264995 \\
0.0008426 \\
0.5072831 \\
0.0789341\end{array}$ & $\begin{array}{r}0.0075764 \\
-0.0001858 \\
0.1025068 \\
0.1405899\end{array}$ & $\begin{array}{r}0.0030333 \\
-0.0003491 \\
-0.4244413 \\
0.8410215\end{array}$ & $\begin{array}{r}0.0018739 \\
-0.0000478 \\
-0.0676436 \\
0.9827538\end{array}$ \\
\hline 2.00 to 4.00 & $\begin{array}{l}0.0536824 \\
0.0021446 \\
0.0005167 \\
0.1189543\end{array}$ & $\begin{array}{l}0.0368921 \\
0.0005244 \\
0.0105851 \\
0.1314398\end{array}$ & $\begin{array}{r}0.0403338 \\
0.0001379 \\
0.6537740 \\
-0.0932544\end{array}$ & $\begin{array}{l}0.0217656 \\
0.0001479 \\
0.0051540 \\
0.0772621\end{array}$ & $\begin{array}{r}0.0090350 \\
-0.0004783 \\
-0.2736292 \\
0.8234569\end{array}$ & $\begin{array}{r}0.0046990 \\
0.0003796 \\
-0.1618472 \\
0.9856915\end{array}$ \\
\hline 4.00 to 6.00 & $\begin{array}{r}0.0424133 \\
0.0051490 \\
0.0005509 \\
-0.2687116\end{array}$ & $\begin{array}{l}0.0346687 \\
0.0020811 \\
0.0045969 \\
0.1078766\end{array}$ & $\begin{array}{r}0.0396506 \\
0.0003325 \\
0.5821891 \\
-0.2627333\end{array}$ & $\begin{array}{r}0.0293448 \\
-0.0001421 \\
0.0456769 \\
0.6521974\end{array}$ & $\begin{array}{r}0.0235230 \\
-0.0004255 \\
-0.4186330 \\
0.8620418\end{array}$ & $\begin{array}{r}0.0136585 \\
0.0003504 \\
-0.1650871 \\
0.9878383\end{array}$ \\
\hline 6.00 to 8.00 & $\begin{array}{r}0.0270956 \\
0.0034819 \\
0.0000925 \\
-0.0929804\end{array}$ & $\begin{array}{l}0.0194425 \\
0.0018932 \\
0.0062071 \\
0.1547564\end{array}$ & $\begin{array}{r}0.0210710 \\
0.0004575 \\
0.4570325 \\
-0.1318118\end{array}$ & $\begin{array}{r}0.0232430 \\
-0.0000806 \\
0.0920852 \\
0.2333674\end{array}$ & $\begin{array}{r}0.0194952 \\
0.0000372 \\
-0.6049687 \\
0.9162310\end{array}$ & $\begin{array}{l}0.0078456 \\
0.0000662 \\
0.0548874 \\
0.9897253\end{array}$ \\
\hline 8.00 to 10.0 & $\begin{array}{r}0.0180805 \\
0.0064786 \\
0.0000806 \\
-0.0711332\end{array}$ & $\begin{array}{l}0.0145099 \\
0.0036072 \\
0.0037420 \\
0.1228438\end{array}$ & $\begin{array}{r}0.0164061 \\
0.0008010 \\
0.3646476 \\
-0.2694049\end{array}$ & $\begin{array}{l}0.0165331 \\
0.0000491 \\
0.0001464 \\
0.2622954\end{array}$ & $\begin{array}{r}0.0167839 \\
0.0000519 \\
-0.6755323 \\
0.8009821\end{array}$ & $\begin{array}{l}0.0106333 \\
0.0001539 \\
0.0651354 \\
0.9894347\end{array}$ \\
\hline${ }^{252} \mathrm{Cf}$ & $\begin{array}{r}0.0492288 \\
0.0011045 \\
0.0001129 \\
-0.1193347\end{array}$ & $\begin{array}{l}0.0288697 \\
0.0000180 \\
0.0188406 \\
0.1884397\end{array}$ & $\begin{array}{r}0.0315514 \\
0.0002632 \\
0.5613750 \\
-0.1341707\end{array}$ & $\begin{array}{r}0.0161952 \\
-0.0000838 \\
0.0631271 \\
0.0375134\end{array}$ & $\begin{array}{r}0.0082183 \\
-0.0001202 \\
-0.4040545 \\
0.8000004\end{array}$ & $\begin{array}{l}0.0045599 \\
0.0000480 \\
0.1344005 \\
0.9837270\end{array}$ \\
\hline 14.00 & $\begin{array}{r}0.0457945 \\
0.0028565 \\
-0.0002029 \\
-0.4082376\end{array}$ & $\begin{array}{l}0.0257283 \\
0.0013726 \\
0.0142216 \\
0.0908468\end{array}$ & $\begin{array}{l}0.0337529 \\
0.0001499 \\
0.4789449 \\
0.0318662\end{array}$ & $\begin{array}{r}0.0240880 \\
0.0000352 \\
-0.0732640 \\
0.2474061\end{array}$ & $\begin{array}{r}0.0149561 \\
0.0000069 \\
-0.4813939 \\
0.8211740\end{array}$ & $\begin{array}{l}0.0073844 \\
0.0001317 \\
0.0096573 \\
0.9870799\end{array}$ \\
\hline
\end{tabular}


TABLE III

Parameters for the 24-Term Approximation of Eq. (15) of the Neutron Albedo for Iron Based on Ambient Dose Equivalent

\begin{tabular}{|c|c|c|c|c|c|c|}
\hline $\begin{array}{l}\text { Energy } \\
(\mathrm{MeV})\end{array}$ & $\begin{array}{r}B_{0} \\
B_{6} \\
B_{12} \\
A_{1,2} \\
\end{array}$ & $\begin{array}{c}B_{1} \\
B_{7} \\
A_{0,0} \\
A_{2,0}\end{array}$ & $\begin{array}{c}B_{2} \\
B_{8} \\
A_{0,1} \\
A_{2,1}\end{array}$ & $\begin{array}{c}B_{3} \\
B_{9} \\
A_{0,2} \\
A_{2,2}\end{array}$ & $\begin{array}{c}B_{4} \\
B_{10} \\
A_{1,0} \\
\kappa_{1}\end{array}$ & $\begin{array}{c}B_{5} \\
B_{11} \\
A_{1,1} \\
\kappa_{2}\end{array}$ \\
\hline 0.10 to 0.20 & $\begin{array}{r}0.0532938 \\
0.0008183 \\
-0.0001396 \\
0.0826687\end{array}$ & $\begin{array}{l}0.0017214 \\
0.0009651 \\
0.0207696 \\
0.1690127\end{array}$ & $\begin{array}{r}0.0047599 \\
-0.0004182 \\
0.4421412 \\
0.4046224\end{array}$ & $\begin{array}{r}0.0017235 \\
0.0002260 \\
-0.1439761 \\
-0.5592011\end{array}$ & $\begin{array}{r}0.0038739 \\
-0.0000209 \\
-0.3949910 \\
0.8364217\end{array}$ & $\begin{array}{l}0.0017985 \\
0.0002403 \\
0.3493605 \\
0.9889952\end{array}$ \\
\hline 0.20 to 0.40 & $\begin{array}{r}0.0428664 \\
0.0014485 \\
0.0000392 \\
-0.2137942\end{array}$ & $\begin{array}{l}0.0057989 \\
0.0011974 \\
0.0166858 \\
0.1167663\end{array}$ & $\begin{array}{r}0.0089092 \\
0.0003991 \\
0.3420655 \\
-0.0682997\end{array}$ & $\begin{array}{r}0.0043192 \\
0.0002262 \\
-0.1078319 \\
0.0249608\end{array}$ & $\begin{array}{r}0.0046892 \\
-0.0003519 \\
-0.5640892 \\
0.8001289\end{array}$ & $\begin{array}{l}0.0021049 \\
0.0001614 \\
0.3592397 \\
0.9832264\end{array}$ \\
\hline 0.40 to 0.60 & $\begin{array}{r}0.0498565 \\
0.0002785 \\
0.0000234 \\
-0.0667203\end{array}$ & $\begin{array}{l}0.0169553 \\
0.0004662 \\
0.0157846 \\
0.0433824\end{array}$ & $\begin{array}{r}0.0158442 \\
-0.0002562 \\
0.5071555 \\
0.1832674\end{array}$ & $\begin{array}{r}0.0065786 \\
-0.0000707 \\
-0.0740615 \\
-0.1338951\end{array}$ & $\begin{array}{r}0.0035137 \\
0.0000887 \\
-0.4392525 \\
0.9221095\end{array}$ & $\begin{array}{l}0.0013000 \\
0.0002501 \\
0.0066950 \\
0.9879640\end{array}$ \\
\hline 0.60 to 0.80 & $\begin{array}{r}0.0541371 \\
-0.0005249 \\
-0.0000638 \\
-0.0802077\end{array}$ & $\begin{array}{r}0.0089104 \\
-0.0002200 \\
0.0249460 \\
0.1451714\end{array}$ & $\begin{array}{r}0.0180305 \\
0.0002923 \\
0.4319382 \\
-0.1225046\end{array}$ & $\begin{array}{r}0.0055529 \\
0.0001070 \\
-0.0812262 \\
0.1561723\end{array}$ & $\begin{array}{r}0.0026773 \\
0.0003477 \\
-0.4565376 \\
0.8074403\end{array}$ & $\begin{array}{l}0.0006289 \\
0.0002955 \\
0.0797066 \\
0.9860243\end{array}$ \\
\hline 0.80 to 1.00 & $\begin{array}{r}0.0273588 \\
0.0001053 \\
-0.0004633 \\
-0.1109212\end{array}$ & $\begin{array}{r}0.0133481 \\
0.0001647 \\
0.0095447 \\
-0.0183574\end{array}$ & $\begin{array}{l}0.0144728 \\
0.0003204 \\
0.2918528 \\
0.0455991\end{array}$ & $\begin{array}{r}0.0051136 \\
-0.0002975 \\
-0.0192545 \\
0.0641485\end{array}$ & $\begin{array}{r}0.0017275 \\
-0.0007973 \\
-0.6169142 \\
0.8594692\end{array}$ & $\begin{array}{r}0.0010622 \\
-0.0003560 \\
-0.0820497 \\
0.9881279\end{array}$ \\
\hline 1.00 to 2.00 & $\begin{array}{r}0.0396122 \\
-0.0000163 \\
0.0000018 \\
-0.4907624\end{array}$ & $\begin{array}{r}0.0160942 \\
-0.0007315 \\
0.0139711 \\
0.1101582\end{array}$ & $\begin{array}{r}0.0254778 \\
-0.0000126 \\
0.4298761 \\
-0.2390671\end{array}$ & $\begin{array}{r}0.0120196 \\
0.0000443 \\
-0.0270629 \\
0.6185012\end{array}$ & $\begin{array}{r}0.0052634 \\
-0.0000793 \\
-0.4854542 \\
0.8405386\end{array}$ & $\begin{array}{l}0.0017163 \\
0.0001041 \\
0.1253156 \\
0.9948031\end{array}$ \\
\hline 2.00 to 4.00 & $\begin{array}{l}0.0699672 \\
0.0051368 \\
0.0006355 \\
0.0104924\end{array}$ & $\begin{array}{l}0.0470624 \\
0.0028880 \\
0.0241450 \\
0.2157251\end{array}$ & $\begin{array}{l}0.0583992 \\
0.0008639 \\
0.7713394 \\
0.2203833\end{array}$ & $\begin{array}{r}0.0477498 \\
-0.0002046 \\
-0.1091949 \\
-0.2757922\end{array}$ & $\begin{array}{r}0.0277122 \\
-0.0002689 \\
-0.3214795 \\
0.8841745\end{array}$ & $\begin{array}{r}0.0129019 \\
0.0006237 \\
-0.3194750 \\
0.9716388\end{array}$ \\
\hline 4.00 to 6.00 & $\begin{array}{r}0.0383584 \\
0.0071172 \\
0.0005182 \\
-0.3777743\end{array}$ & $\begin{array}{l}0.0333513 \\
0.0021780 \\
0.0076436 \\
0.0800085\end{array}$ & $\begin{array}{r}0.0406763 \\
-0.0002839 \\
0.4048834 \\
-0.0077119\end{array}$ & $\begin{array}{r}0.0382366 \\
-0.0000926 \\
-0.0392213 \\
0.2373894\end{array}$ & $\begin{array}{r}0.0271660 \\
0.0003122 \\
-0.5529857 \\
0.8427911\end{array}$ & $\begin{array}{r}0.0151085 \\
0.0007226 \\
-0.0688028 \\
0.9886515\end{array}$ \\
\hline 6.00 to 8.00 & $\begin{array}{r}0.0366453 \\
0.0132009 \\
0.0003877 \\
-0.1807104\end{array}$ & $\begin{array}{l}0.0363076 \\
0.0056037 \\
0.0079033 \\
0.1021265\end{array}$ & $\begin{array}{l}0.0463791 \\
0.0007640 \\
0.4434946 \\
0.0179065\end{array}$ & $\begin{array}{r}0.0448332 \\
-0.0009652 \\
-0.0716627 \\
0.0781227\end{array}$ & $\begin{array}{r}0.0363180 \\
-0.0001809 \\
-0.5959346 \\
0.8637481\end{array}$ & $\begin{array}{r}0.0242095 \\
0.0008290 \\
-0.1655178 \\
0.9811557\end{array}$ \\
\hline 8.00 to 10.0 & $\begin{array}{r}0.0235136 \\
0.0140041 \\
0.0005766 \\
-0.3756055\end{array}$ & $\begin{array}{l}0.0251327 \\
0.0075519 \\
0.0074658 \\
0.0988650\end{array}$ & $\begin{array}{l}0.0334662 \\
0.0028613 \\
0.3461263 \\
0.0051997\end{array}$ & $\begin{array}{r}0.0336685 \\
0.0002568 \\
-0.0148531 \\
0.2985481\end{array}$ & $\begin{array}{r}0.0291116 \\
-0.0001438 \\
-0.7061847 \\
0.8757374\end{array}$ & $\begin{array}{r}0.0219503 \\
0.0000136 \\
-0.0741588 \\
0.9869155\end{array}$ \\
\hline${ }^{252} \mathrm{Cf}$ & $\begin{array}{r}0.0459410 \\
0.0076217 \\
-0.0006190 \\
-0.2609887\end{array}$ & $\begin{array}{l}0.0242135 \\
0.0061894 \\
0.0155636 \\
0.1593948\end{array}$ & $\begin{array}{r}0.0329226 \\
0.0037884 \\
0.4976990 \\
-0.3307752\end{array}$ & $\begin{array}{r}0.0331010 \\
0.0009262 \\
-0.1072952 \\
0.3993058\end{array}$ & $\begin{array}{r}0.0318835 \\
-0.0008405 \\
-0.5499798 \\
0.8123170\end{array}$ & $\begin{array}{r}0.0149376 \\
-0.0001239 \\
-0.0629111 \\
0.9947029\end{array}$ \\
\hline 14.00 & $\begin{array}{r}0.0128098 \\
-0.0004953 \\
0.0000611 \\
-0.0257022\end{array}$ & $\begin{array}{l}0.0174085 \\
0.0004738 \\
0.0138527 \\
0.1951785\end{array}$ & $\begin{array}{r}0.0166469 \\
0.0004850 \\
0.1844362 \\
-0.1405954\end{array}$ & $\begin{array}{r}0.0083089 \\
-0.0001278 \\
0.2328879 \\
0.0531641\end{array}$ & $\begin{array}{r}0.0014990 \\
-0.0003312 \\
-0.8331926 \\
0.8620238\end{array}$ & $\begin{array}{r}-0.0007495 \\
-0.0002862 \\
0.1608196 \\
0.9869965\end{array}$ \\
\hline
\end{tabular}


TABLE IV

Parameters for the 24-Term Approximation of Eq. (15) of the Neutron Albedo for Lead Based on Ambient Dose Equivalent

\begin{tabular}{|c|c|c|c|c|c|c|}
\hline $\begin{array}{l}\text { Energy } \\
(\mathrm{MeV})\end{array}$ & $\begin{array}{c}B_{0} \\
B_{6} \\
B_{12} \\
A_{1,2}\end{array}$ & $\begin{array}{c}B_{1} \\
B_{7} \\
A_{0,0} \\
A_{2,0}\end{array}$ & $\begin{array}{c}B_{2} \\
B_{8} \\
A_{0,1} \\
A_{2,1}\end{array}$ & $\begin{array}{c}B_{3} \\
B_{9} \\
A_{0,2} \\
A_{2,2}\end{array}$ & $\begin{array}{c}B_{4} \\
B_{10} \\
A_{1,0} \\
\kappa_{1}\end{array}$ & $\begin{array}{c}B_{5} \\
B_{11} \\
A_{1,1} \\
\kappa_{2}\end{array}$ \\
\hline 0.10 to 0.20 & $\begin{array}{r}0.0558987 \\
-0.0000269 \\
0.0000056 \\
0.0281927\end{array}$ & $\begin{array}{r}0.0023528 \\
-0.0000076 \\
0.0211978 \\
0.0666451\end{array}$ & $\begin{array}{r}0.0024396 \\
0.0000198 \\
0.5874357 \\
-0.0789938\end{array}$ & $\begin{array}{r}0.0006283 \\
-0.0000241 \\
-0.1463577 \\
0.0592571\end{array}$ & $\begin{array}{r}0.0002252 \\
-0.0000023 \\
-0.3633696 \\
0.8116018\end{array}$ & $\begin{array}{r}0.0005829 \\
0.0000176 \\
-0.2294366 \\
0.9912418\end{array}$ \\
\hline 0.20 to 0.40 & $\begin{array}{r}0.0500629 \\
0.0002355 \\
-0.0001222 \\
-0.0238649\end{array}$ & $\begin{array}{r}0.0042147 \\
-0.0000006 \\
0.0171735 \\
0.0226677\end{array}$ & $\begin{array}{r}0.0045578 \\
0.0000737 \\
0.5094106 \\
-0.0800756\end{array}$ & $\begin{array}{r}0.0019449 \\
-0.0000236 \\
-0.1322565 \\
0.0924186\end{array}$ & $\begin{array}{r}0.0015217 \\
-0.0000842 \\
-0.4581400 \\
0.8022838\end{array}$ & $\begin{array}{r}0.0009231 \\
0.0000151 \\
-0.1971223 \\
0.9830990\end{array}$ \\
\hline 0.40 to 0.60 & $\begin{array}{r}0.0572949 \\
0.0005229 \\
-0.0000863 \\
-0.0181668\end{array}$ & $\begin{array}{l}0.0072558 \\
0.0002147 \\
0.0151566 \\
0.0556704\end{array}$ & $\begin{array}{r}0.0093308 \\
-0.0003718 \\
0.6345752 \\
-0.0204593\end{array}$ & $\begin{array}{r}0.0064029 \\
-0.0001010 \\
-0.1400677 \\
0.0473351\end{array}$ & $\begin{array}{r}0.0060143 \\
-0.0002718 \\
-0.3631013 \\
0.8779085\end{array}$ & $\begin{array}{r}0.0020942 \\
-0.0000931 \\
-0.1609658 \\
0.9912042\end{array}$ \\
\hline 0.60 to 0.80 & $\begin{array}{r}0.0374910 \\
0.0004225 \\
-0.0005456 \\
-0.1155415\end{array}$ & $\begin{array}{l}0.0064014 \\
0.0004135 \\
0.0106124 \\
0.0328702\end{array}$ & $\begin{array}{r}0.0086570 \\
-0.0004770 \\
0.4169844 \\
-0.0593905\end{array}$ & $\begin{array}{r}0.0073005 \\
-0.0000946 \\
-0.0916683 \\
0.1271705\end{array}$ & $\begin{array}{r}0.0066616 \\
0.0000506 \\
-0.5844201 \\
0.8536718\end{array}$ & $\begin{array}{r}0.0015417 \\
-0.0002702 \\
-0.1010548 \\
0.9887343\end{array}$ \\
\hline 0.80 to 1.00 & $\begin{array}{r}0.0584633 \\
0.0014475 \\
-0.0007575 \\
0.1666693\end{array}$ & $\begin{array}{l}0.0130224 \\
0.0009744 \\
0.0158747 \\
0.0526834\end{array}$ & $\begin{array}{r}0.0183176 \\
-0.0004953 \\
0.6515040 \\
0.1836432\end{array}$ & $\begin{array}{r}0.0161752 \\
-0.0000157 \\
-0.1677025 \\
-0.1818777\end{array}$ & $\begin{array}{r}0.0149129 \\
-0.0000858 \\
-0.3263391 \\
0.8018481\end{array}$ & $\begin{array}{r}0.0038738 \\
-0.0000673 \\
-0.3792064 \\
0.9938379\end{array}$ \\
\hline 1.00 to 2.00 & $\begin{array}{r}0.0530010 \\
0.0016786 \\
-0.0006660 \\
-0.0459249\end{array}$ & $\begin{array}{l}0.0188155 \\
0.0009315 \\
0.0197107 \\
0.0385525\end{array}$ & $\begin{array}{r}0.0267216 \\
-0.0002921 \\
0.5819071 \\
0.3035811\end{array}$ & $\begin{array}{r}0.0250196 \\
0.0003044 \\
-0.0596983 \\
-0.1487739\end{array}$ & $\begin{array}{r}0.0237658 \\
-0.0003449 \\
-0.3944350 \\
0.8542292\end{array}$ & $\begin{array}{r}0.0055260 \\
0.0000121 \\
-0.2676750 \\
0.9925053\end{array}$ \\
\hline 2.00 to 4.00 & $\begin{array}{r}0.0397078 \\
0.0065428 \\
0.0003421 \\
-0.2001542\end{array}$ & $\begin{array}{l}0.0267902 \\
0.0031976 \\
0.0106837 \\
0.0771358\end{array}$ & $\begin{array}{l}0.0383964 \\
0.0011212 \\
0.4601275 \\
0.0189377\end{array}$ & $\begin{array}{r}0.0381639 \\
0.0001523 \\
-0.0459297 \\
0.3086182\end{array}$ & $\begin{array}{r}0.0359253 \\
-0.0011819 \\
-0.6127313 \\
0.9307469\end{array}$ & $\begin{array}{r}0.0168128 \\
-0.0005838 \\
-0.2896862 \\
0.9831710\end{array}$ \\
\hline 4.00 to 6.00 & $\begin{array}{r}0.0429480 \\
0.0254998 \\
-0.0006500 \\
-0.3539149\end{array}$ & $\begin{array}{l}0.0390275 \\
0.0156083 \\
0.0070241 \\
0.0308492\end{array}$ & $\begin{array}{l}0.0537080 \\
0.0085227 \\
0.4809715 \\
0.0258892\end{array}$ & $\begin{array}{r}0.0568942 \\
0.0033289 \\
-0.0589891 \\
0.2674945\end{array}$ & $\begin{array}{r}0.0538668 \\
-0.0009162 \\
-0.5612269 \\
0.8908337\end{array}$ & $\begin{array}{r}0.0404909 \\
-0.0014155 \\
-0.2228249 \\
0.9806583\end{array}$ \\
\hline 6.00 to 8.00 & $\begin{array}{r}0.0338077 \\
0.0313908 \\
-0.0006031 \\
0.0002879\end{array}$ & $\begin{array}{r}0.0308618 \\
0.0232711 \\
-0.0056719 \\
-0.0241546\end{array}$ & $\begin{array}{l}0.0413024 \\
0.0170424 \\
0.5490080 \\
0.3607939\end{array}$ & $\begin{array}{r}0.0467627 \\
0.0112588 \\
-0.1058596 \\
0.1003439\end{array}$ & $\begin{array}{r}0.0471813 \\
0.0047711 \\
-0.5172456 \\
0.9443846\end{array}$ & $\begin{array}{r}0.0410459 \\
0.0005880 \\
-0.5892470 \\
0.9975493\end{array}$ \\
\hline 8.00 to 10.0 & $\begin{array}{l}0.0198070 \\
0.0199688 \\
0.0019843 \\
0.1691786\end{array}$ & $\begin{array}{r}0.0140910 \\
0.0171652 \\
0.0081692 \\
-0.0049809\end{array}$ & $\begin{array}{l}0.0175012 \\
0.0148174 \\
0.2576149 \\
0.3300473\end{array}$ & $\begin{array}{r}0.0213214 \\
0.0132233 \\
-0.0022423 \\
-0.3745058\end{array}$ & $\begin{array}{r}0.0231222 \\
0.0097253 \\
-0.7766307 \\
0.9147022\end{array}$ & $\begin{array}{r}0.0225639 \\
0.0051359 \\
-0.3020114 \\
0.9732737\end{array}$ \\
\hline${ }^{252} \mathrm{Cf}$ & $\begin{array}{r}0.0111404 \\
0.0096794 \\
-0.0000275 \\
-0.0203116\end{array}$ & $\begin{array}{l}0.0133828 \\
0.0062412 \\
0.0043138 \\
0.0870102\end{array}$ & $\begin{array}{r}0.0146153 \\
0.0034405 \\
0.1994782 \\
-0.1643755\end{array}$ & $\begin{array}{l}0.0148671 \\
0.0015927 \\
0.0061004 \\
0.0782730\end{array}$ & $\begin{array}{r}0.0149662 \\
0.0006972 \\
-0.8403319 \\
0.8010939\end{array}$ & $\begin{array}{l}0.0131436 \\
0.0002460 \\
0.0224057 \\
0.9826734\end{array}$ \\
\hline 14.00 & $\begin{array}{r}0.0396915 \\
0.0406900 \\
-0.0019741 \\
-0.4895494\end{array}$ & $\begin{array}{l}0.0374025 \\
0.0314361 \\
0.0191170 \\
0.2610349\end{array}$ & $\begin{array}{l}0.0501896 \\
0.0230933 \\
0.5675920 \\
0.3805100\end{array}$ & $\begin{array}{r}0.0557815 \\
0.0149423 \\
0.1735340 \\
-0.0003166\end{array}$ & $\begin{array}{r}0.0559450 \\
0.0062647 \\
-0.6088180 \\
0.9800740\end{array}$ & $\begin{array}{r}0.0501798 \\
0.0011605 \\
-0.0213167 \\
0.9948286\end{array}$ \\
\hline
\end{tabular}


TABLE V

Parameters for the 24-Term Approximation of Eq. (15) of the Neutron Albedo for Water Based on Ambient Dose Equivalent

\begin{tabular}{|c|c|c|c|c|c|c|}
\hline $\begin{array}{l}\text { Energy } \\
(\mathrm{MeV})\end{array}$ & $\begin{array}{c}B_{0} \\
B_{6} \\
B_{12} \\
A_{1,2}\end{array}$ & $\begin{array}{c}B_{1} \\
B_{7} \\
A_{0,0} \\
A_{2,0}\end{array}$ & $\begin{array}{c}B_{2} \\
B_{8} \\
A_{0,1} \\
A_{2,1}\end{array}$ & $\begin{array}{c}B_{3} \\
B_{9} \\
A_{0,2} \\
A_{2,2}\end{array}$ & $\begin{array}{c}B_{4} \\
B_{10} \\
A_{1,0} \\
\kappa_{1}\end{array}$ & $\begin{array}{c}B_{5} \\
B_{11} \\
A_{1,1} \\
\kappa_{2}\end{array}$ \\
\hline 0.10 to 0.20 & $\begin{array}{r}0.0129219 \\
-0.0009612 \\
-0.0000893 \\
0.0334064\end{array}$ & $\begin{array}{r}0.0203124 \\
-0.0007030 \\
0.0036126 \\
0.1729190\end{array}$ & $\begin{array}{r}0.0203507 \\
-0.0001533 \\
0.4117485 \\
0.1066032\end{array}$ & $\begin{array}{r}0.0133489 \\
0.0000032 \\
0.0827997 \\
-0.4833454\end{array}$ & $\begin{array}{r}0.0052986 \\
-0.0000561 \\
-0.6838040 \\
0.8967318\end{array}$ & $\begin{array}{r}0.0005921 \\
-0.0001328 \\
0.0550869 \\
0.9901377\end{array}$ \\
\hline 0.20 to 0.40 & $\begin{array}{r}0.0184540 \\
-0.0011766 \\
-0.0003576 \\
0.2890114\end{array}$ & $\begin{array}{r}0.0243669 \\
-0.0005657 \\
0.0120361 \\
0.3064913\end{array}$ & $\begin{array}{r}0.0266709 \\
-0.0002026 \\
0.4492530 \\
-0.0450006\end{array}$ & $\begin{array}{r}0.0175327 \\
-0.0000695 \\
0.1897889 \\
-0.3401521\end{array}$ & $\begin{array}{r}0.0064331 \\
-0.0002964 \\
-0.6425737 \\
0.8451869\end{array}$ & $\begin{array}{r}0.0004416 \\
-0.0005765 \\
-0.0350966 \\
0.9562095\end{array}$ \\
\hline 0.40 to 0.60 & $\begin{array}{r}0.0115668 \\
-0.0009023 \\
0.0000077 \\
0.0948313\end{array}$ & $\begin{array}{r}0.0166603 \\
-0.0001264 \\
0.0079243 \\
0.1604304\end{array}$ & $\begin{array}{l}0.0147648 \\
0.0001958 \\
0.2082212 \\
0.0968823\end{array}$ & $\begin{array}{r}0.0076651 \\
0.0002109 \\
0.1332742 \\
-0.3261282\end{array}$ & $\begin{array}{r}0.0021182 \\
0.0001216 \\
-0.7846735 \\
0.8592585\end{array}$ & $\begin{array}{r}-0.0005477 \\
-0.0000306 \\
0.0996876 \\
0.9824912\end{array}$ \\
\hline 0.60 to 0.80 & $\begin{array}{r}0.0182030 \\
-0.0004657 \\
0.0000239 \\
0.0507981\end{array}$ & $\begin{array}{r}0.0269427 \\
-0.0000652 \\
0.0049888 \\
0.1954288\end{array}$ & $\begin{array}{l}0.0237484 \\
0.0001062 \\
0.4634968 \\
0.1470037\end{array}$ & $\begin{array}{r}0.0142403 \\
-0.0002561 \\
0.3571756 \\
-0.5248015\end{array}$ & $\begin{array}{r}0.0046316 \\
-0.0002065 \\
-0.6575601 \\
0.9595597\end{array}$ & $\begin{array}{l}0.0001613 \\
0.0000119 \\
0.2666836 \\
0.9688572\end{array}$ \\
\hline 0.80 to 1.00 & $\begin{array}{r}0.0141696 \\
-0.0011356 \\
-0.0000137 \\
0.0376798\end{array}$ & $\begin{array}{r}0.0166203 \\
-0.0006341 \\
0.0056358 \\
0.2119139\end{array}$ & $\begin{array}{r}0.0180389 \\
-0.0002396 \\
0.2789036 \\
0.1314868\end{array}$ & $\begin{array}{r}0.0098593 \\
-0.0001605 \\
0.1977545 \\
-0.0684558\end{array}$ & $\begin{array}{r}0.0023972 \\
-0.0003385 \\
-0.7653953 \\
0.9245704\end{array}$ & $\begin{array}{r}-0.0005659 \\
-0.0001092 \\
0.0953145 \\
0.9800317\end{array}$ \\
\hline 1.00 to 2.00 & $\begin{array}{r}0.0164421 \\
-0.0015547 \\
0.0001882 \\
0.1940659\end{array}$ & $\begin{array}{r}0.0207049 \\
-0.0001573 \\
0.0077076 \\
0.2269972\end{array}$ & $\begin{array}{l}0.0215597 \\
0.0005514 \\
0.3279836 \\
0.1750762\end{array}$ & $\begin{array}{r}0.0092660 \\
0.0002771 \\
0.2694326 \\
-0.0551756\end{array}$ & $\begin{array}{r}0.0007758 \\
-0.0001149 \\
-0.7092761 \\
0.9105451\end{array}$ & $\begin{array}{r}-0.0020370 \\
-0.0000278 \\
-0.1326348 \\
0.9915097\end{array}$ \\
\hline 2.00 to 4.00 & $\begin{array}{r}0.0226896 \\
-0.0009443 \\
0.0004094 \\
-0.1594746\end{array}$ & $\begin{array}{l}0.0313581 \\
0.0008327 \\
0.0103071 \\
0.2574273\end{array}$ & $\begin{array}{r}0.0291665 \\
0.0009503 \\
0.4304798 \\
-0.0209579\end{array}$ & $\begin{array}{r}0.0135662 \\
-0.0002490 \\
0.4783325 \\
0.3672793\end{array}$ & $\begin{array}{r}0.0003836 \\
-0.0004774 \\
-0.6627982 \\
0.9669937\end{array}$ & $\begin{array}{r}-0.0025622 \\
-0.0001232 \\
0.0418333 \\
0.9876719\end{array}$ \\
\hline 4.00 to 6.00 & $\begin{array}{l}0.0165370 \\
0.0007730 \\
0.0000037 \\
0.1634773\end{array}$ & $\begin{array}{l}0.0238119 \\
0.0015651 \\
0.0121924 \\
0.1745254\end{array}$ & $\begin{array}{l}0.0210479 \\
0.0011396 \\
0.2629612 \\
0.0287459\end{array}$ & $\begin{array}{r}0.0106129 \\
0.0001474 \\
0.2150514 \\
-0.1913277\end{array}$ & $\begin{array}{r}0.0034434 \\
-0.0001968 \\
-0.7965685 \\
0.8380902\end{array}$ & $\begin{array}{r}0.0010876 \\
-0.0001304 \\
-0.0144339 \\
0.9891834\end{array}$ \\
\hline 6.00 to 8.00 & $\begin{array}{l}0.0148640 \\
0.0021364 \\
0.0002195 \\
0.2762631\end{array}$ & $\begin{array}{l}0.0201575 \\
0.0027179 \\
0.0110018 \\
0.1484251\end{array}$ & $\begin{array}{l}0.0163847 \\
0.0010844 \\
0.2889479 \\
0.4382038\end{array}$ & $\begin{array}{r}0.0111439 \\
0.0000464 \\
0.2411449 \\
-0.5486105\end{array}$ & $\begin{array}{r}0.0051654 \\
0.0000689 \\
-0.8271057 \\
0.9078802\end{array}$ & $\begin{array}{r}0.0010073 \\
0.0001915 \\
-0.2590476 \\
0.9725868\end{array}$ \\
\hline 8.00 to 10.0 & $\begin{array}{l}0.0149725 \\
0.0022414 \\
0.0000906 \\
0.6601474\end{array}$ & $\begin{array}{l}0.0203694 \\
0.0018008 \\
0.0091251 \\
0.1653099\end{array}$ & $\begin{array}{l}0.0171314 \\
0.0003975 \\
0.3496518 \\
0.5326599\end{array}$ & $\begin{array}{r}0.0105427 \\
-0.0001573 \\
0.2914835 \\
-0.7786617\end{array}$ & $\begin{array}{r}0.0065417 \\
-0.0000975 \\
-0.7279292 \\
0.9327370\end{array}$ & $\begin{array}{r}0.0029309 \\
0.0000669 \\
-0.2725006 \\
0.9961565\end{array}$ \\
\hline${ }^{252} \mathrm{Cf}$ & $\begin{array}{r}0.0371479 \\
0.0323403 \\
0.0064871 \\
-1.3685842\end{array}$ & $\begin{array}{r}0.0258430 \\
0.0323324 \\
-0.0072767 \\
-0.0238093\end{array}$ & $\begin{array}{r}0.0307108 \\
0.0322866 \\
0.4471703 \\
-0.7921728\end{array}$ & $\begin{array}{r}0.0308909 \\
0.0313035 \\
-0.0214340 \\
1.5318002\end{array}$ & $\begin{array}{r}0.0317781 \\
0.0258584 \\
-0.5745561 \\
0.8808124\end{array}$ & $\begin{array}{l}0.0326513 \\
0.0166355 \\
0.4863048 \\
0.9998973\end{array}$ \\
\hline 14.00 & $\begin{array}{r}0.0128763 \\
0.0056577 \\
-0.0000637 \\
0.7385826\end{array}$ & $\begin{array}{l}0.0209132 \\
0.0028383 \\
0.0009609 \\
0.0801827\end{array}$ & $\begin{array}{l}0.0192572 \\
0.0008183 \\
0.3134141 \\
0.4249718\end{array}$ & $\begin{array}{r}0.0143676 \\
0.0000196 \\
0.1612224 \\
-0.6998956\end{array}$ & $\begin{array}{r}0.0111819 \\
0.0000215 \\
-0.7289138 \\
0.9121793\end{array}$ & $\begin{array}{r}0.0087258 \\
-0.0000210 \\
-0.4863645 \\
0.9937053\end{array}$ \\
\hline
\end{tabular}




\section{Concrete}
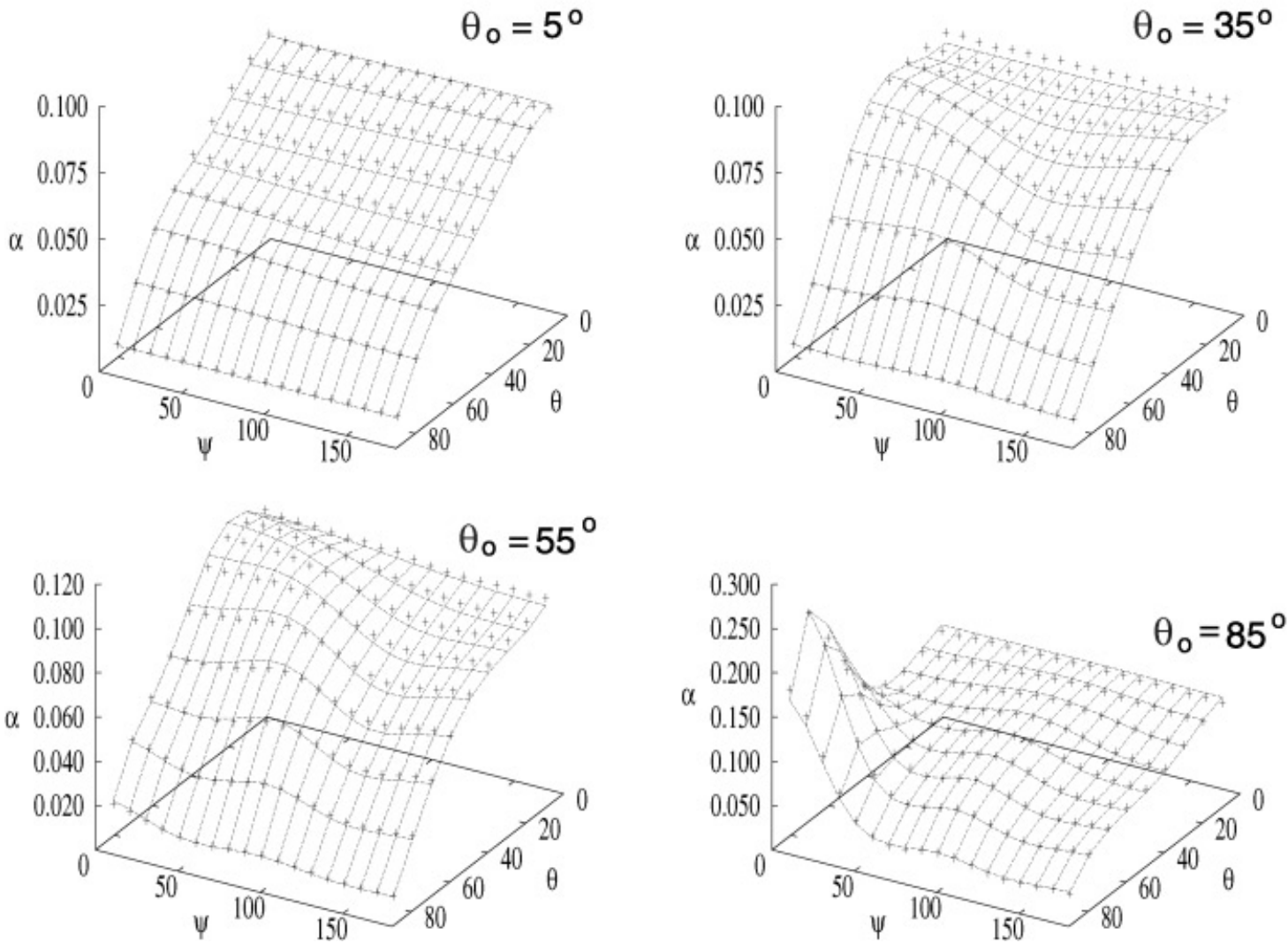

Fig. 4. Neutron differential ambient-dose-equivalent albedo $\alpha_{D}\left(E_{o}, \theta_{o} ; \theta, \psi\right)$ for 6- to 8-MeV neutrons incident on a slab of concrete for $\theta_{o}=5,35,55$, and $85 \mathrm{deg}$. Comparison of MCNP results (crosses) and the results obtained using the approximation of Eq. (15) (surface).

TABLE VI

Parameters for the Five-Term Approximation of Eq. (17) for the Ambient Dose Equivalent for Secondary Photons from Concrete

\begin{tabular}{|l|c|c|r|r|r|}
\hline $\begin{array}{c}\text { Energy } \\
(\mathrm{MeV})\end{array}$ & $A_{1}$ & $A_{2}$ & & $A_{3}$ & \multicolumn{1}{c|}{$A_{4}$} \\
\hline 0.10 to 0.20 & 1.2256033 & 0.0638375 & 0.1287182 & -0.0365617 & 0.0137941 \\
0.20 to 0.40 & 1.2328238 & 0.0218045 & 0.0417456 & -0.0102296 & 0.0203584 \\
0.40 to 0.60 & 1.2478099 & 0.1814403 & 0.0733548 & 0.1078396 & 0.0022300 \\
0.60 to 0.80 & 1.2597181 & 0.0507181 & 0.1065247 & -0.0262779 & 0.0056767 \\
0.80 to 1.00 & 1.2604353 & 0.0218006 & 0.0396005 & -0.0101063 & 0.0109961 \\
1.00 to 2.00 & 1.1804842 & 0.0345058 & 0.0422212 & -0.0119163 & 0.0077079 \\
2.00 to 4.00 & 0.9267063 & 0.5350051 & 0.0652701 & -0.1112095 & 0.0010900 \\
4.00 to 6.00 & 0.8145848 & 0.4692991 & -0.3926117 & 0.2092658 & 0.0022836 \\
6.00 to 8.00 & 0.6978850 & 0.1410359 & -0.1356589 & 0.0612874 & 0.0117359 \\
8.00 to 10.0 & 0.6228144 & 0.0861592 & -0.0837287 & 0.0349653 & 0.0250683 \\
Thermal & 0.6683126 & 0.2879494 & 0.2936914 & -0.1094149 & 0.0998052 \\
$252 \mathrm{Cf}$ & 0.9308342 & 0.0430707 & -0.0140312 & 0.0095817 & 0.0139569 \\
14.00 & 0.6149221 & 0.0851669 & -0.0743139 & 0.0271471 & 0.0294899 \\
\hline
\end{tabular}


TABLE VII

Parameters for the Five-Term Approximation of Eq. (17) for the Ambient Dose Equivalent for Secondary Photons from Iron

\begin{tabular}{|c|c|c|c|c|c|}
\hline $\begin{array}{l}\text { Energy } \\
(\mathrm{MeV})\end{array}$ & $A_{1}$ & $A_{2}$ & $A_{3}$ & $A_{4}$ & $A_{5}$ \\
\hline 0.10 to 0.20 & 0.8727888 & 0.3910898 & -0.1651363 & 0.0705975 & 0.0006783 \\
\hline 0.20 to 0.40 & 0.8868781 & 0.1682039 & -0.0892619 & 0.0421833 & 0.0007284 \\
\hline 0.40 to 0.60 & 0.8977394 & 0.0637598 & -0.0159727 & 0.0013926 & 0.0010851 \\
\hline 0.60 to 0.80 & 0.8745456 & 0.1903683 & -0.1307043 & 0.0501842 & 0.0004495 \\
\hline 0.80 to 1.00 & 0.8765674 & 0.0403735 & -0.0417100 & 0.0173702 & 0.0060748 \\
\hline 1.00 to 2.00 & 0.8257353 & 0.8330504 & -0.9675792 & 0.4149715 & 0.0007585 \\
\hline 2.00 to 4.00 & 0.7707039 & 0.0321307 & -0.0335682 & 0.0126081 & 0.0442171 \\
\hline 4.00 to 6.00 & 0.7122030 & 0.5731707 & -0.6470894 & 0.2664282 & 0.0054015 \\
\hline 6.00 to 8.00 & 0.6969441 & 0.0559594 & -0.0626762 & 0.0247631 & 0.0735622 \\
\hline 8.00 to 10.0 & 0.6942459 & 0.1688198 & -0.1956101 & 0.0782608 & 0.0261653 \\
\hline Thermal & 0.4764265 & 0.7414173 & 0.0931285 & -0.1350677 & 0.1645858 \\
\hline${ }^{252} \mathrm{Cf}$ & 0.7553329 & 1.1404155 & -1.1852769 & 0.4367836 & 0.0010909 \\
\hline 14.00 & 0.7365907 & 0.7625878 & -0.9469593 & 0.4063371 & 0.0051079 \\
\hline
\end{tabular}

TABLE VIII

Parameters for the Five-Term Approximation of Eq. (17) for the Ambient Dose Equivalent for Secondary Photons from Lead

\begin{tabular}{|l|c|c|c|c|c|}
\hline $\begin{array}{c}\text { Energy } \\
(\mathrm{MeV})\end{array}$ & $A_{1}$ & $A_{2}$ & $A_{3}$ & $A_{4}$ & $A_{5}$ \\
\hline 0.10 to 0.20 & 0.9625199 & 1.5401880 & -2.1370354 & 1.5138557 & 0.0000189 \\
0.20 to 0.40 & 1.0064926 & 8.8446321 & -9.9999504 & 5.2171597 & 0.0000019 \\
0.40 to 0.60 & 0.9896619 & 8.0910301 & -9.9999886 & 5.0190039 & 0.0000024 \\
0.60 to 0.80 & 0.9639104 & 7.0908947 & -9.9279041 & 5.1394620 & 0.0000051 \\
0.80 to 1.00 & 0.9711326 & 0.0958014 & -0.1438290 & 0.0793675 & 0.0003579 \\
1.00 to 2.00 & 0.9178385 & 0.3052734 & -0.4916002 & 0.2621346 & 0.0004646 \\
2.00 to 4.00 & 0.8245898 & 0.3646463 & -0.5314746 & 0.2586226 & 0.0016356 \\
4.00 to 6.00 & 0.7945315 & 0.1351111 & -0.2158038 & 0.1084514 & 0.0156090 \\
6.00 to 8.00 & 0.8075593 & 1.9551373 & -3.3866832 & 1.8079202 & 0.0017540 \\
8.00 to 10.0 & 0.8159494 & 0.0736450 & -0.1292748 & 0.0696660 & 0.0422499 \\
Thermal & 0.8293945 & 0.9605026 & -0.8077921 & 0.3992487 & 0.0109283 \\
252 Cf & 0.8174528 & 0.0310898 & -0.0489764 & 0.0248023 & 0.0206109 \\
14.00 & 0.8536811 & 0.0453257 & -0.0766899 & 0.0400009 & 0.0404982 \\
\hline
\end{tabular}

If a thermal neutron streaming through a duct reaches the duct surface, the albedo can be used to obtain the weight and direction of any particle reflected from the surface. The albedo needed for such a calculation is the differential "number" albedo. This albedo, denoted by $\alpha\left(\theta_{o} ; \theta, \psi\right)$, is defined as in Eqs. (1) through (4) but with $R(E)=1$; i.e., the flows refer to the number of particles flowing through a unit area of the surface. ${ }^{1}$ For thermal neutrons the number albedo equals the dose albedo since the thermal-neutron response function $R\left(E_{t h}\right)$ cancels out in the dose ratio of Eq. (3).
As a particle streams through a duct, the orientation of the surface from which the particle is reflected is different at each point of reflection. Therefore, to construct a transport code that uses albedo techniques, a method must be developed for transforming from the global coordinate system to the local coordinate system of the reflection point, and back again. ${ }^{24}$

When a thermal neutron traveling in a duct with weight $W_{o}$ hits the duct surface, the rejection technique can be applied to the number albedo to obtain the reflected directions $\theta$ and $\psi$ with respect to a local 
TABLE IX

Parameters for the Five-Term Approximation of Eq. (17) for the Ambient Dose Equivalent for Secondary Photons from Water

\begin{tabular}{|l|c|c|c|c|c|}
\hline $\begin{array}{c}\text { Energy } \\
(\mathrm{MeV})\end{array}$ & $A_{1}$ & $A_{2}$ & $A_{3}$ & $A_{4}$ & $A_{5}$ \\
\hline 0.10 to 0.20 & 0.6407247 & 0.0593760 & 0.1594001 & -0.0452385 & 0.0226027 \\
0.20 to 0.40 & 0.6655912 & 0.0094389 & 0.0252501 & -0.0079355 & 0.0858675 \\
0.40 to 0.60 & 0.6886491 & 0.0164475 & 0.0474505 & -0.0165714 & 0.0348122 \\
0.60 to 0.80 & 0.7123201 & 0.0230588 & 0.0749818 & -0.0302738 & 0.0220694 \\
0.80 to 1.00 & 0.7340014 & 0.0432483 & 0.1365578 & -0.0597300 & 0.0108535 \\
1.00 to 2.00 & 0.7691070 & 0.0241902 & 0.0775496 & -0.0357483 & 0.0184533 \\
2.00 to 4.00 & 0.8417001 & 0.2769863 & 0.9282053 & -0.5249802 & 0.0017484 \\
4.00 to 6.00 & 0.9106550 & 0.0213192 & 0.0754003 & -0.0494900 & 0.0240043 \\
6.00 to 8.00 & 0.7757766 & 0.6343027 & 0.7231793 & -0.5882518 & 0.0011233 \\
8.00 to 10.0 & 0.6168484 & 0.2000332 & 0.0335462 & -0.0756631 & 0.0047815 \\
Thermal & 0.3471366 & 0.0873124 & 0.1643816 & -0.0394940 & 0.1095107 \\
252 Cf & 0.7872421 & 0.0460545 & 0.1462282 & -0.0758350 & 0.0109788 \\
14.00 & 0.6069419 & 0.1044084 & -0.0126468 & -0.0186599 & 0.0118985 \\
\hline
\end{tabular}

\section{Concrete}
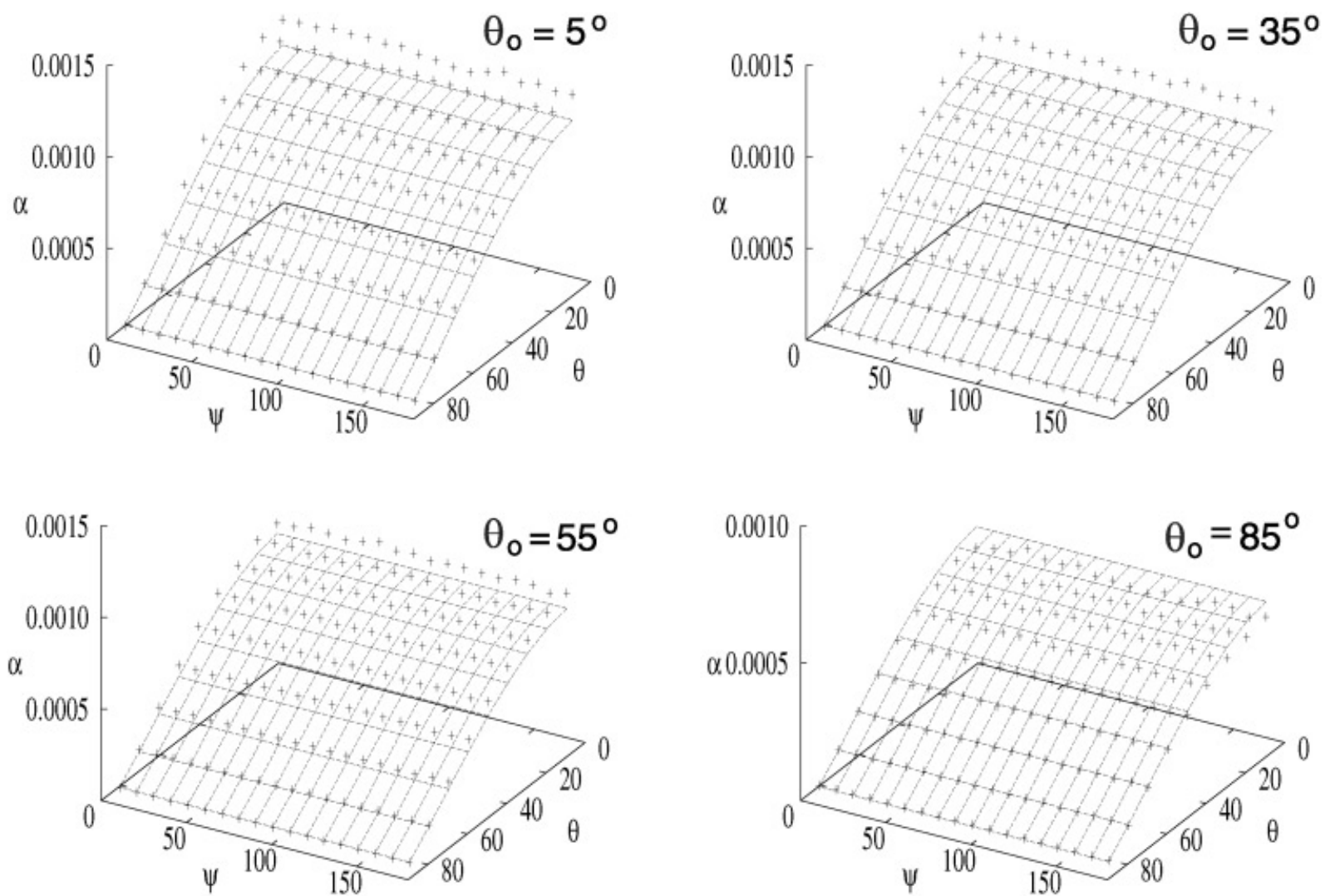

Fig. 5. The differential secondary-photon effective-dose-equivalent (AP) albedo $\alpha_{D}\left(E_{o}, \theta_{o} ; \theta, \psi\right)$ for 1 - to 2-MeV monodirectional neutrons incident on a slab of concrete for $\theta_{o}=5,35,55$, and $85 \mathrm{deg}$. Comparison of MCNP results (crosses) and the results obtained using the approximation of Eq. (17) (surface). 
coordinate system, and these directions are then transformed back to the global coordinate system. The tracking of the particle through the duct continues with the particle's weight adjusted for the probability $\alpha\left(\theta_{o}\right)$ that the neutron is reflected, namely,

$$
\alpha\left(\theta_{o}\right)=\int_{0}^{\pi / 2} \sin \theta d \theta \int_{0}^{2 \pi} \alpha\left(\theta_{o} ; \theta, \psi\right) d \psi
$$

The weight of the particle reflected from the surface is thus changed to

$$
W=\alpha\left(\theta_{o}\right) W_{o} .
$$

To score the response along the centerline of the duct, a last-flight estimator is used. With this estimator, contributions to the tally are made each time a particle collides with a surface of the duct. The probability that the particle is reflected into a solid angle $d \Omega$ about $\boldsymbol{\Omega}(\theta, \psi)$, for a given angle of incidence $\theta_{o}$, is $\alpha\left(\theta_{o} ; \theta, \psi\right) d \Omega$. Furthermore, $d \Omega$ can be expressed as

$$
d \Omega=d A / R^{2},
$$

where $R$ is the distance between the reflection point and the tally location and $d A$ is an element of area at the detector location normal to a straight line drawn between the point of reflection and the tally position. In the albedo method, it is assumed that no interactions occur as the neutron streams through the duct volume. Then, because the fluence can be defined as the number of particles passing through a unit area normal to the scattering direction, Eqs. (19) and (20) can be combined to give the fluence contribution to tally as

$$
\Phi_{r}=W \alpha\left(\theta_{o} ; \theta_{D}, \psi_{D}\right) / R^{2},
$$

where

$$
\begin{aligned}
\Phi_{r} & =\text { fluence at the detector } \\
W= & \text { weight of the reflected particle } \\
\theta_{D}= & \text { polar angle with respect to the detector location } \\
\psi_{D}= & \text { azimuthal angle with respect to the detector } \\
& \text { location. }
\end{aligned}
$$

\section{V.A. Comparison to a Benchmark Experiment}

In 1967 Maerker and Muckenthaler calculated the dose along the centerline of a three-legged duct, for thermal neutrons incident at the duct mouth, using a hybrid Monte Carlo technique. ${ }^{25}$ More important, they performed a benchmark experiment at the Oak Ridge National Laboratory Tower Shielding Facility with the same source and duct geometries, the results of which they then compared with the results of their hybrid Monte Carlo calculations. The geometry used in their experiments and calculations is shown in Fig. 6.

As one test to validate the albedo results presented here, we modified MCNP to use our albedo approximation for thermal neutrons to also calculate the centerline

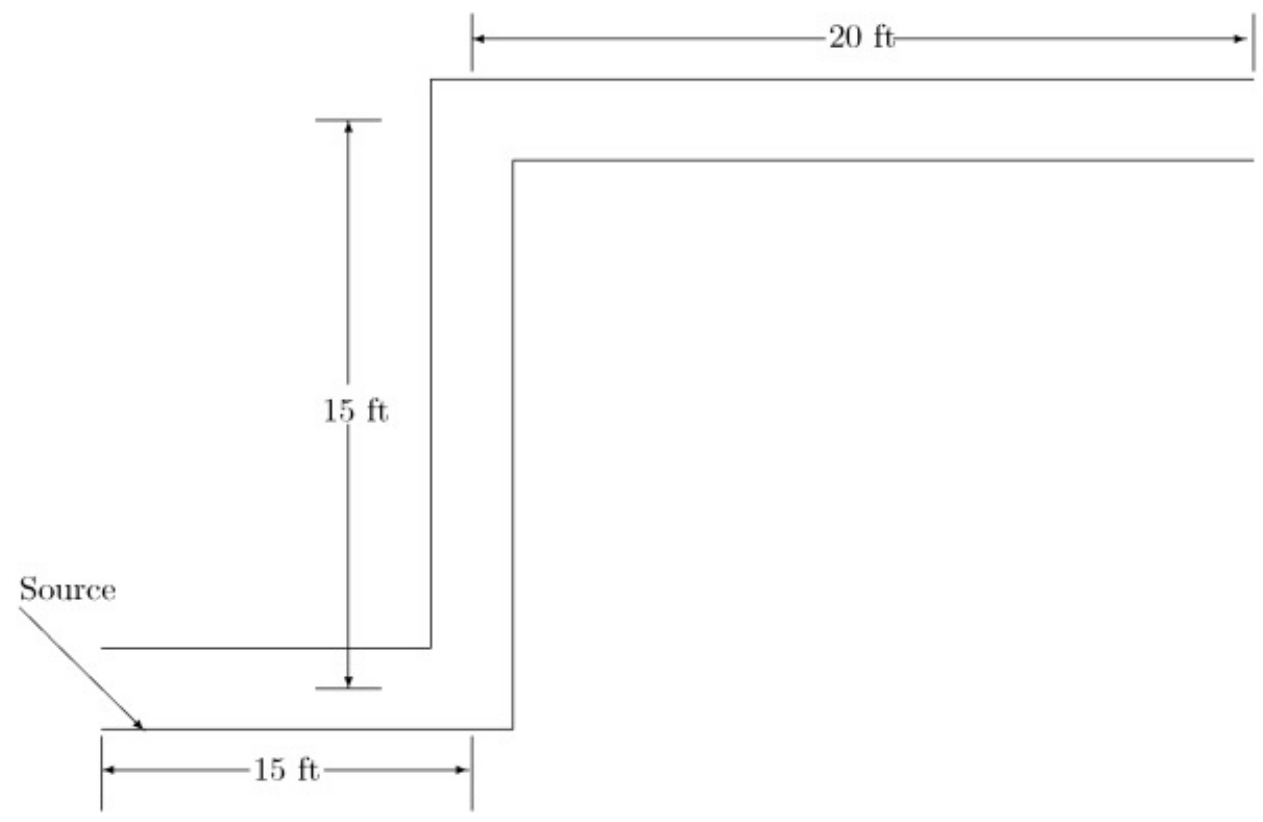

Fig. 6. Geometry for the benchmark duct experiment. ${ }^{25}$ The cross section of the square duct is $0.91 \times 0.91 \mathrm{~m}(3 \times 3 \mathrm{ft})$, and the lengths of the first, second, and third legs are 4.57, 4.57, and $6.10 \mathrm{~m}(15,15$, and $20 \mathrm{ft})$, respectively. The steel-reinforced concrete walls are $22.9 \mathrm{~cm}$ (9 in.) thick. A tightly collimated source of thermal neutrons is incident at the duct entrance at an angle of 45 deg to one duct wall. 


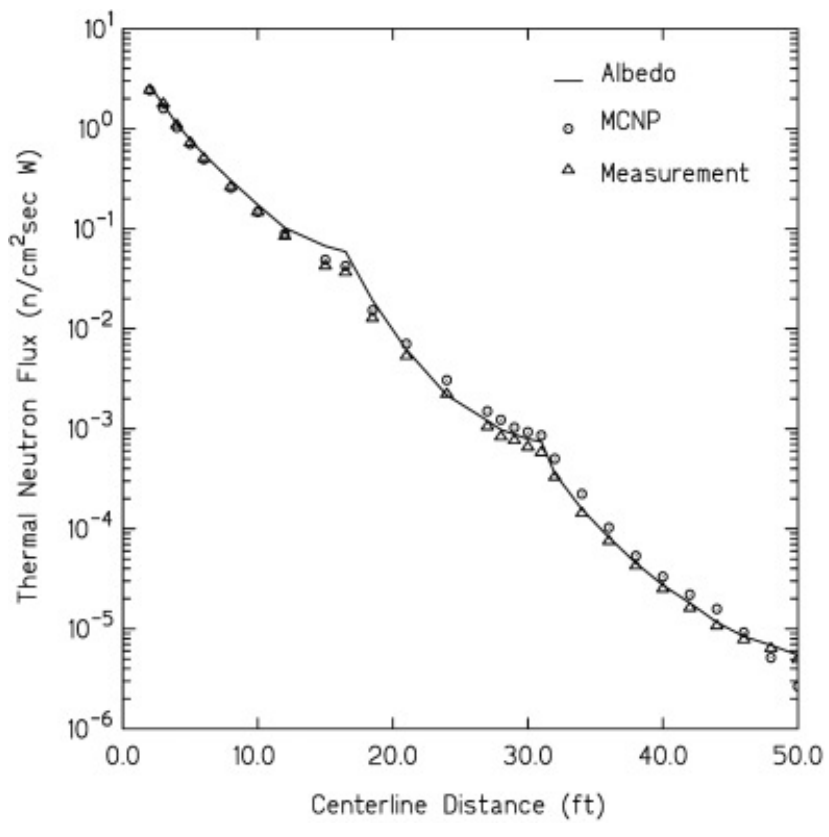

Fig. 7. Comparison of MCNP, albedo-modified MCNP, and measured results as a function of centerline distance in feet from the mouth of a three-legged duct.

doses in the benchmark duct. The patches to the MCNP code to use the albedo technique and the input file are presented by Brockhoff. ${ }^{24}$ The results are compared with the experimental measurements obtained by Maerker and Muckenthaler in Fig. 7. It can be seen that overall the modified MCNP results (line) agree well with both the experimental results (triangles) and results obtained with an unmodified MCNP simulation (circles). Minor differences between the measurements and our MCNP results we believe can be attributed to slight differences in the concrete compositions. It is also seen that the albedomodified MCNP results tend to overestimate slightly the response in the vicinity of the duct bends, particularly at the first bend. This overprediction arises because the neutrons are actually more likely to penetrate through the corners than to be reflected back toward the detector. Requirement (2) of Sec. I, namely, that the reflecting medium be optically thick, is not true at a corner, and consequently, the albedo method overpredicts the reflected component.

The hybrid albedo technique is far more efficient than the unmodified version of MCNP for the solution of multileg duct problems. For the problem presented here, the unmodified version of MCNP required $638 \mathrm{~min}$ of CPU time, compared to $73 \mathrm{~min}$ of CPU time for the hybrid technique for the same number of histories.

\section{CONCLUSIONS}

The albedo concept can be a very effective analysis technique for particle-streaming problems. The new al- bedo approximation presented here is capable of representing the differential dose albedo within $10 \%$. More important, data have been developed based on modern dosimetric units and modern cross-section data for four different reflecting materials.

Although space limitations have restricted the data presented here to that for single-dose response functions, data are available for $\alpha_{D}\left(E_{o} ; \theta, \psi\right)$ based on (a) Henderson (tissue kerma), (b) ambient dose equivalent, and (c) effective dose equivalent (anteroposterior) response functions. These data are available at ww2.mne. ksu.edu/ jks/papers.htm.

\section{REFERENCES}

1. J. K. SHULTIS and R. E. FAW, Radiation Shielding, American Nuclear Society, La Grange Park, Illinois (2000).

2. R. E. MAERKER and F. J. MUCKENTHALER, "Calculation and Measurement of the Fast-Neutron Differential Dose Albedo for Concrete," Nucl. Sci. Eng., 22, 455 (1965).

3. R. E. ALLEN, A. FUTTERER, and W. WRIGHT, Reports BRL-1148 (1961), BRL-1189 (1963), BRL-1190 (1963), BRL-1199 (1963), BRL-1204 (1963), BRL-1224 (1963), and BRL-1238 (1964), Ballistic Research Laboratory.

4. R. L. FRENCH and M. B. WELLS, "An Angular Dependent Albedo for Fast-Neutron Reflection Calculations," RRAM31, Radiation Research Associates (1963).

5. Y. T. SONG, C. M. HUDDLESTON, and A. B. CHILTON, "Differential Dose Albedo for Fast Neutrons," Nucl. Sci. Eng., 35, 401 (1969).

6. G. L. SIMMONS, T. E. ALBERT, and M. L. GRITZNER, "The SAI/EPRI Albedo Information Library," SAI-013-79525-LJ (RSICC Code Collection DLC-57), Science Applications, Inc.

7. V. R. CAIN and M. B. EMMETT, "BREESE-II: Auxiliary Routines for Implementing the Albedo Option in the MORSE Monte Carlo Code," ORNL/TM-6807 (RSICC Code Collection PSR 143), Oak Ridge National Laboratory (1979).

8. X. WANG, "Neutron and Secondary Gamma Ray Reflection and Transmission Properties of Concrete," MS Thesis, Kansas State University (1993).

9. W. A. COLEMAN, R. E. MAERKER, F. J. MUCKENTHALER, and P. N. STEVENS, "Calculation of Doubly Differential Current Albedos for Epicadmium Neutrons Incident on Concrete and Comparison of the Subcadmium Component with Experiment," Nucl. Sci. Eng., 27, 411 (1967).

10. M. B. WELLS, "Reflection of Thermal Neutrons and Neutron-Capture Gamma Rays from Concrete," RRA-M44, Radiation Research Associates (1964). 
11. R. E. MAERKER and F. J. MUCKENTHALER, "Measurements and Single-Velocity Calculations of Differential Angular Thermal-Neutron Albedos for Concrete," Nucl. Sci. Eng., 26, 339 (1966).

12. S. CHANDRASEKHAR, Radiative Transfer, Dover Publications, New York (1960).

13. L. V. SPENCER, J. A. DIAZ, and E. MOSES, "Neutron Penetration in Cylindrical Ducts," NBS 8542, U.S. National Bureau of Standards (1964).

14. W. E. SELPH, "Albedos, Ducts and Voids," Reactor Shielding for Nuclear Engineers, Chap. 7, TID 25951, N. M. SCHAEFFER, Ed., National Technical Information Service, U.S. Department of Commerce, Springfield, Virginia (1973).

15. G. P. CAVANAUGH, "A Calculation and Analysis of Albedos Due to 14-MeV Neutrons Incident on Concrete," PhD Dissertation, University of Illinois at Urbana-Champaign (1975).

16. G. J. HENDERSON, "Conversion of Neutron or Gamma Ray Flux to Absorbed Dose Rate," XDC-59-8-179, U.S. Atomic Energy Commission (1959).

17. "Protection Against Neutron Radiation, Recommendations of the National Council on Radiation Protection and Measurements," Report 38, National Council on Radiation Protection and Measurements (1971).
18. "Data for Use in Protection Against External Radiation," Publication 51, Ann. ICRP, 17, $2 / 3$ (1987).

19. "Conversion Coefficients for Use in Radiological Protection Against External Radiation," Publication 51, Ann. ICRP, 26, $3 / 4$ (1996).

20. R. E. FAW and J. K. SHULTIS, Radiological Assessment: Sources and Doses, American Nuclear Society, La Grange Park, Illinois (1999).

21. X-5 MONTE CARLO TEAM, "MCNP-A General Purpose Monte Carlo N-Particle Transport Code, Version 5," Vol. II, User's Guide, LA-CP-03-0245, Los Alamos National Laboratory (2003).

22. "Guidelines on the Nuclear Analysis and Design of Concrete Radiation Shielding for Nuclear Power Plants," ANSI/ ANS-6.4-1985, American National Standards Institute (1985).

23. W. H. PRESS, S. A. TEUKOLSKY, W. T. VETTERLING, and B. P. FLANNEY, Numerical Recipes, 2nd ed., Cambridge University Press, Cambridge, United Kingdom (1992).

24. R. C. BROCKHOFF, "Calculation of Albedos for Neutrons and Photons," PhD Dissertation, Kansas State University (2003).

25. R. E. MAERKER and F. J. MUCKENTHALER, "Neutron Fluxes in Concrete Ducts Arising from Incident Thermal Neutrons," Nucl. Sci. Eng., 29, 444 (1967). 